\title{
High-density lipoproteins suppress $A \beta$ - induced PBMC adhesion to human endothelial cells in bioengineered vessels and in monoculture
}

Jérôme Robert ${ }^{1,2+} \mathbb{B}$, Emily B. Button ${ }^{1,2+}$, Sophie Stukas ${ }^{1,2}$, Guilaine K. Boyce ${ }^{1,2}$, Ebrima Gibbs ${ }^{2,3}$, Catherine M. Cowan ${ }^{4}$, Megan Gilmour ${ }^{1,2}$, Wai Hang Cheng ${ }^{1,2}$, Sonja K. Soo ${ }^{1,2}$, Brian Yuen ${ }^{1,2}$, Arvin Bahrabadi ${ }^{1,2}$, Kevin Kang ${ }^{1,2}$, Iva Kulic ${ }^{1,2}$, Gordon Francis ${ }^{5}$, Neil Cashman ${ }^{2,3}$ and Cheryl L. Wellington ${ }^{1,2^{*}}$

\begin{abstract}
Background: Alzheimer's Disease (AD), characterized by accumulation of beta-amyloid (A $\beta$ ) plaques in the brain, can be caused by age-related failures to clear $A \beta$ from the brain through pathways that involve the cerebrovasculature. Vascular risk factors are known to increase AD risk, but less is known about potential protective factors. We hypothesize that high-density lipoproteins (HDL) may protect against $A D$, as $H D L$ have vasoprotective properties that are well described for peripheral vessels. Epidemiological studies suggest that HDL is associated with reduced $\mathrm{AD}$ risk, and animal model studies support a beneficial role for $\mathrm{HDL}$ in selectively reducing cerebrovascular amyloid deposition and neuroinflammation. However, the mechanism by which HDL may protect the cerebrovascular endothelium in the context of $A D$ is not understood.

Methods: We used peripheral blood mononuclear cell adhesion assays in both a highly novel three dimensional (3D) biomimetic model of the human vasculature composed of primary human endothelial cells (EC) and smooth muscle cells cultured under flow conditions, as well as in monolayer cultures of ECs, to study how HDL protects ECs from the detrimental effects of $A \beta$.

Results: Following $A \beta$ addition to the abluminal (brain) side of the vessel, we demonstrate that HDL circulated within the lumen attenuates monocyte adhesion to ECs in this biofidelic vascular model. The mechanism by which HDL suppresses A $\beta$-mediated monocyte adhesion to ECs was investigated using monotypic EC cultures. We show that HDL reduces $A \beta$-induced PBMC adhesion to ECs independent of nitric oxide (NO) production, miR-233 and changes in adhesion molecule expression. Rather, $\mathrm{HDL}$ acts through scavenger receptor (SR)-BI to block A $\beta$ uptake into ECs and, in cell-free assays, can maintain A $\beta$ in a soluble state. We confirm the role of SR-BI in our bioengineered human vessel.
\end{abstract}

Conclusion: Our results define a novel activity of HDL that suppresses A $\beta$-mediated monocyte adhesion to the cerebrovascular endothelium.

Keywords: Alzheimer's disease, Beta-amyloid, High-density lipoprotein, Engineered vessel, Endothelial cells

\footnotetext{
* Correspondence: wcheryl@mail.ubc.ca

${ }^{\dagger}$ Equal contributors

'Department of Pathology and Laboratory Medicine, University of British

Columbia, Vancouver, BC V6T 123, Canada

${ }^{2}$ Djavad Mowafaghian Centre for Brain Health, University of British Columbia,

2215 Wesbrook Mall, Vancouver, BC V6T 1Z3, Canada

Full list of author information is available at the end of the article
} 


\section{Background}

Alzheimer's disease (AD) is the leading cause of dementia with over 44 million affected persons worldwide and has no effective treatment [1]. AD is believed to arise from the toxic effects of amyloidogenic beta-amyloid peptides $(A \beta)$, which form higher order structures including oligomers and fibrils that accumulate as amyloid plaques in the brain parenchyma and cerebral vessels [2]. The role of the cerebrovasculature in AD has gained increased recognition in the last decade, as AD risk is increased by vascular risk factors, including hypertension, type 2 diabetes mellitus (T2DM), and hypercholesterolemia [3-5]. Most AD autopsy cases have evidence of cerebral small vessel disease, including cerebral amyloid angiopathy (CAA) and microvascular degeneration, with micro- and macro-infarcts reported in over $80 \%$ of very old AD subjects [6]. The cerebrovasculature plays a pivotal role in clearing $A \beta$ from the brain [7], and activation of cerebrovascular endothelial cells (ECs) has been reported in AD brain [8].

High-density lipoproteins (HDL) are a heterogeneous mixture of circulating lipoprotein particles that are composed of, in addition to apoA-I, cholesterol and phospholipids, over 200 lipid species and at least 95 proteins in normolipidemic plasma $[9,10]$. Intriguingly, the elevated concentration of plasma high-density lipoprotein cholesterol (HDL-C), which is associated with reduced cardiovascular disease risk [11], is also negatively correlated with cognitive decline [12]. Preclinical studies also support a beneficial role of HDL on the cerebrovasculature. Specifically, transgenic overexpression of human apoA-I, the major protein component on HDL, from its endogenous promoter in the liver and intestine, reduces neuroinflammation, improves cognitive function and selectively reduces cerebrovascular amyloid in the APP/ PS1 model of amyloidosis, whereas deletion of apoA-I, the major protein component of HDL, has the opposite effects $[13,14]$. We recently reported that a single intravenous injection of reconstituted HDL reduces soluble brain $A \beta 40$ and $A \beta 42$ levels after $24 \mathrm{~h}$ in symptomatic APP/PS1 mice [15].

Systemically circulating HDL may therefore benefit the brain, however, the mechanisms by which it may do so are unknown. HDL is well established to possess several potent vasoprotective functions in peripheral vascular endothelial cells (ECs) including reducing inflammation, increasing vascular tone through promoting endothelial nitric oxide (NO) synthase activity, and suppressing vascular adhesion molecule expression [16]. Using peripheral blood mononuclear cell (PBMC) adherence assays, here we show that $\mathrm{A} \beta$ induces $\mathrm{PMBC}$ adhesion, a classical measure of EC activation, in cerebral microvascular ECs through a mechanism distinct from classical inflammatory stimulation by tumor necrosis factor-alpha (TNF- $\alpha)$. We also demonstrate that HDL robustly suppresses $A \beta$ induced monocyte adhesion to ECs both in monolayer cultures as well as in a novel 3 dimensional (3D) tissue engineered human vessel.

\section{Methods}

Fabrication of tissue engineered vessels

Scaffold-directed human engineered vessels were generated under flow bioreactor conditions as described [17]. Briefly, non-woven polyglycolic-acid meshes (PGA; BMS) were coated with polycoprolactone (PCL, Purac) and polyglycolic acid (PLA, Purac) by dipping into a $1.75 \%(w / w / w)$ solution of PCL/PLA/tetrahydrofuran (Sigma Aldrich). A tubular shape (length $10 \mathrm{~mm}$ and inner diameter $2 \mathrm{~mm}$ ) was obtained by heat welding be-

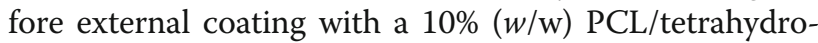
furan solution. After sterilization with $70 \%$ ethanol for 30 min followed by 3 washes with PBS, scaffolds were pre-incubated in advanced DMEM overnight before cell seeding. Human umbilical cord smooth muscle cells were isolated as described [17] and $2 \times 10^{6} \mathrm{cells} / \mathrm{cm}^{2}$ were seeded in the inner surface of the vascular scaffold using fibrinogen $(10 \mathrm{mg} / \mathrm{mL}$ clottable protein, Sigma Aldrich) and thrombin (10 mU) as cell carriers [18]. After a short static incubation period of 3 days, vascular constructs were exposed to dynamic conditioning in a flow bioreactor, where the flow of nutrient medium (Advanced DMEM (Invitrogen) with 10\% FBS; 0.05\% Penicillin/Streptomycin, 1\% L-glutamine and $1.5 \mathrm{mM} \mathrm{L-}$ ascorbic acid) was directed through the inner lumen of the bioreactor circulation loop at $6 \mathrm{~mL} / \mathrm{min}$. After 14 days of flow conditioning, vascular grafts were endothelialzed with HUVECs $\left(1.5 \times 10^{6}\right.$ cells $\left./ \mathrm{cm}^{2}\right)$ seeded into the lumen followed by cultivation under static conditions for 5 days in complete endothelial growth medium (EBM-2; Lonza) supplemented with $10 \%$ foetal bovine serum (FBS) and growth supplements to form EGM complete media FBS. After the static phase, vascular grafts were placed back in the bioreactor for 14 additional days with increasing medium flow (4 to $6 \mathrm{~mL} / \mathrm{min}$ ) in complete EGM-2 with $10 \% \mathrm{FBS}$.

\section{Characterization of engineered vascular tissue}

For histological characterization, engineered vessels were fixed in formalin (Fisher), dehydrated through a graded ethanol series using a Sakura Tissue Processor (Sakura), embedded in paraffin and sectioned at $7 \mu \mathrm{m}$ thickness. Sections were deparaffinised, rehydrated through a graded ethanol series and stained using haematoxylin \& eosin (SigmaAldrich) following the manufacture's instructions. For immunofluorescence analyses, tissues were cryopreserved in Cryomatrix (ThermoFisher) and sectioned at $20 \mu \mathrm{m}$ thickness using a cryotome (Leica). Immunostaining was performed as described [17] using 
antibodies specific for the EC marker CD31 (clone JC/ 70A Biolegend, 1:50) and $\alpha$-smooth muscle actin (clone 1A4 SigmaAldrich, 1:200). Sections were counter-stained with DAPI and imaged with an inverted microscope (Carl Zeiss). Endothelium barrier integrity was analyzed by injecting Evans blue (Sigma Aldrich) at a final concentration of $0.5 \%$ in the circulation loop of the bioreactor for 10 min followed by continuous PBS washing for $20 \mathrm{~min}$. Vessels were cut open longitudinally and en face preparations were analysed macroscopically with photo documentation.

\section{Preparation of $\mathrm{HDL}$ and PBMCs}

All experiments were conducted under an approved clinical protocol (UBC Clinical Ethics Research Board H14-03357). Upon receipt of written informed consent, $100 \mathrm{~mL}$ of fasted blood was collected from normolipidemic healthy donors into vacutainer tubes. Plasma HDL $(1.063-1.21 \mathrm{~g} / \mathrm{mL})$ was isolated by sequential potassium bromide gradient ultracentrifugation as described [19]. The purity of the HDL preparations was verified by sodium dodecyl sulphate-polyacrylamide gel electrophoresis (SDS-PAGE) followed by Coomassie blue staining to ensure no low-density lipoprotein (LDL) or albumin contamination. Eight independent donors were used across the experiments, 6 isolated in-house and 2 commercially obtained (Leebioscience). Human-derived, lipid free apoA-I was a kind gift from CSL-Behring. Immortalized human THP1 monocytes (ATCC) were cultured in RPMI containing 10\% FBS, $1 \%$ Pen/Strep, $2 \mathrm{mM} \mathrm{L}$ glutamine and $0.1 \% \beta$-mercaptoethanol. Primary human PBMC were isolated from healthy donors by centrifugation on a continuous density gradient (Lymphoprep ${ }^{\mathrm{Tw}}$, Stemcell) following the manufacturer's instructions. Freshly isolated PBMC were fluorescently labeled with $10 \mu \mathrm{M}$ of Cell-Tracker Red for $30 \mathrm{~min}$ (Invitrogen) following the manufacturer's recommendations.

\section{Monocyte adhesion in engineered vessels}

Vascular grafts were perfused with complete EGM-2 with $2 \%$ FBS. $1 \mu \mathrm{M} A \beta 42$ or $A \beta 40$ monomers were injected directly into the graft chamber to mimic $A \beta$ originating from the brain (antelumen) side of the vessel. At time points ranging from 2 to $72 \mathrm{~h}$, THP1 cells were fluorescently labeled with Cell-Tracker Red as described above, injected in the graft circulation at a concentration of $1 \times 10^{6}$ cells $/ \mathrm{mL}$ and maintained under flow conditions for $3 \mathrm{~h}$. For HDL experiments, vascular grafts were perfused with luminal HDL $(200 \mu \mathrm{g} / \mathrm{mL})$ for $2 \mathrm{~h}$ before injecting $A \beta$ in the antelumen side for $8 \mathrm{~h}$. Tissues were longitudinally cut open, washed extensively with PBS and fixed with 4\% PFA. After $20 \mathrm{~min}$, tissues were washed 3 times with PBS and mounted in Prolong Gold antifade reagent with DAPI. For each independently seeded tissue, adherent monocytes and monocytes undergoing diapedesis were counted in 3 random squares of $1.23 \mathrm{~mm}^{2}$ using a $\mathrm{z}$-stack covering the whole tissue thickness with a SP8 confocal microscope (Leica), averaged and expressed as percent of vehicle normalized to $100 \%$ for Fig. $1 \mathrm{~d}$ and $\mathrm{f}$ or percent of $\mathrm{A} \beta$ normalized to 100\% for Fig. $1 \mathrm{~h}$ and j, and Fig. 8a and b.

\section{Static monotypic cell culture}

hCMEC/D3 (Fisher; passage 27-35), and HUVEC (passage 4-7, isolated as described [17]) cells were cultured using complete EGM-2 with $2 \%$ FBS, ECs were cultured in a humidified incubator at $37{ }^{\circ} \mathrm{C}$ at $5 \%$ carbon dioxide. For mechanistic experiments, ECs were treated with SRBI blocking antibody (NB440-113 Novus, 1:500), the SR-BI inhibitor block lipid transport-1 (BLT-1, SigmaAldrich, $10 \mu \mathrm{M}$ ), the eNOS inhibitor L-NG-nitroarginne methyl ester (L-NAME, SigmaAldrich, $1 \mathrm{mM}$ ), the receptor associated protein (RAP, Oxford biome, $1 \mu \mathrm{M}$ ), the RAGE blocking antibody (176,902, R\&D Systems, 1:50), heparin $(10 \mathrm{mU})$, heparinase (SigmaAldrich, $0.2 \mathrm{mM}$ ) or the CD36 blocking antibody (JC63.1, ABCAM, 1:500) for $1 \mathrm{~h}$ before HDL priming. For miRNA experiments, cells were transiently transfected using Lipofectamine 2000 (Life Technology) $2 \mathrm{~h}$ before A $\beta$ stimulation with the miR-223 mimetic (Life Technology, 4,464,066 (MC12301), $100 \mathrm{nM}$ ) or miR-223 inhibitor (Life Technology, 4,464,084 (MH12301), $100 \mathrm{nM}$ ) in EBM-2 containing 0.2\% BSA.

\section{Monolayer PBMC adhesion assay}

ECs were seeded at $1 \times 10^{5}$ cells/well in 24-well plates and cultured until confluent for 2 to 3 days. On the day of the assay, ECs were primed for $2 \mathrm{~h}$ with $100 \mu \mathrm{g} / \mathrm{mL}$ bovine serum albumin as vehicle control or $100 \mu \mathrm{g} / \mathrm{mL}$ HDL before stimulation with $1 \mathrm{ng} / \mathrm{mL}$ of TNF- $\alpha$ (Preprotech) or various concentrations of monomeric $A \beta 40$ and $A \beta 42$ (0.001-1 $\mu \mathrm{M}$, California Peptide), prepared as described below. After 3 h, $5 \times 10^{5}$ Cell-Tracker Red-labeled PBMC per well were added to ECs for 3 additional hours before washing 3 times with $\mathrm{PBS}$ to remove non-adherent PBMC. Cells were then fixed with 4\% PFA for 15 min before 3 additional PBS washes and 4',6-diamidino-2-phenylindole (DAPI) counterstaining. For each independent experiment, adherent monocytes were counted in 5 random squares of $7.84 \mathrm{~mm}^{2}$ using a fluorescent inverted microscope (Zeiss), averaged and expressed as percent of vehicle normalized to $100 \%$. DAPI counterstaining was used to ensure endothelial cell coverage.

\section{$A \beta$ oligomerization/fibrilization and electron microscopy confirmation}

Recombinant $A \beta 40$ and $A \beta 42$ peptides (California Peptide) were dissolved in ice-cold hexafluoroisopropanol (HFIP). 
a

Bioreactor
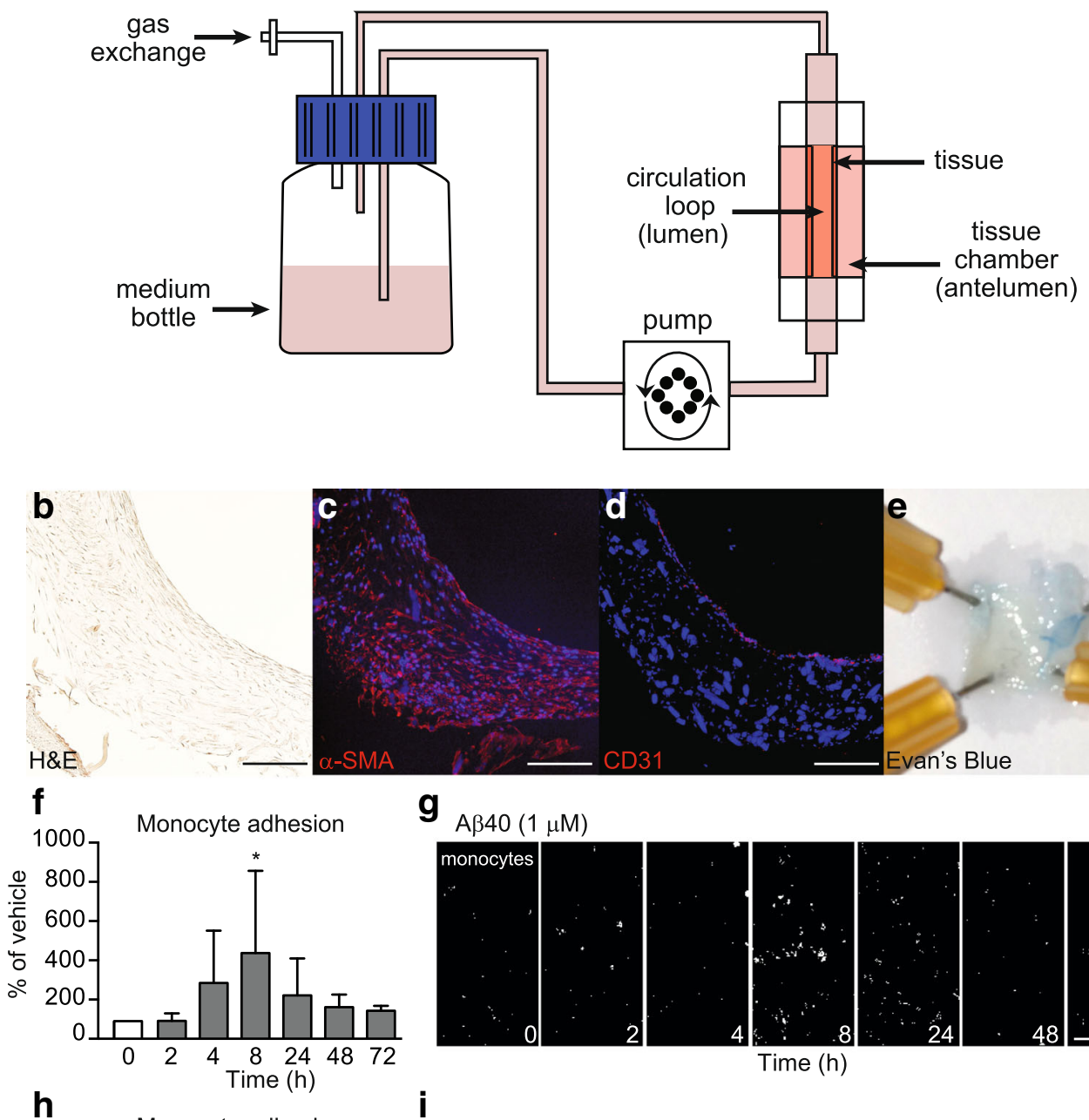

$9_{\mathrm{A} \beta 40(1 \mu \mathrm{M})}$
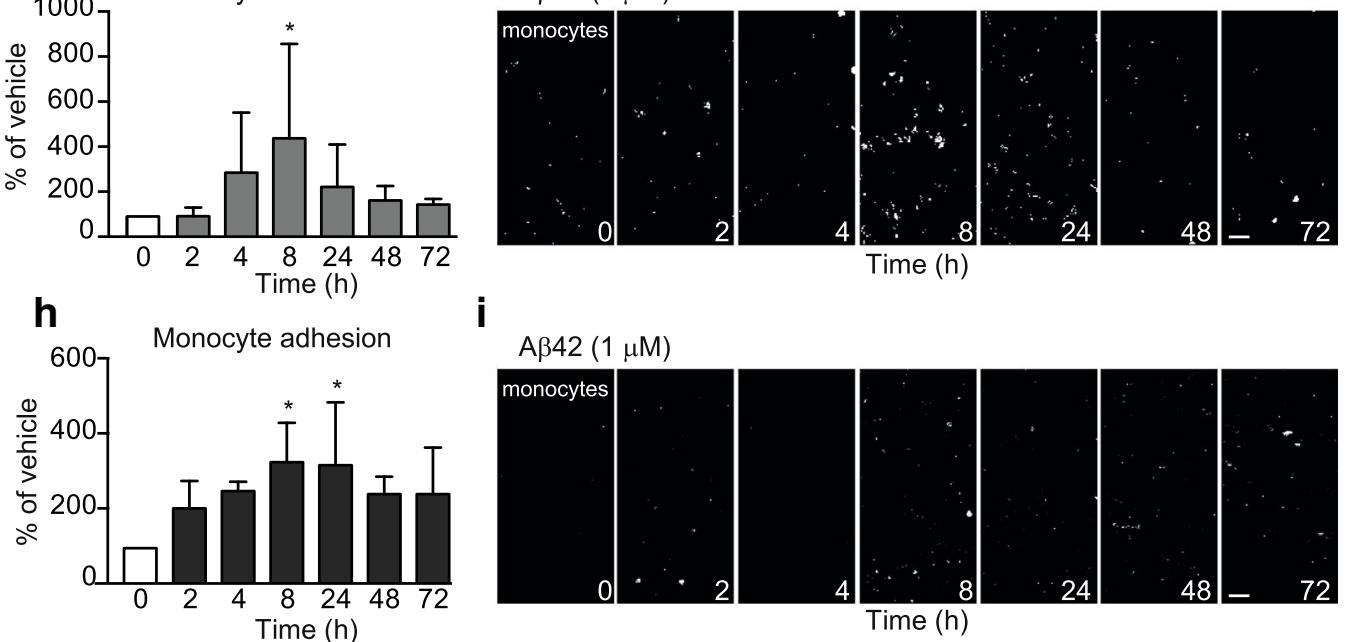

$\mathrm{A} \beta 42(1 \mu \mathrm{M})$

j

k
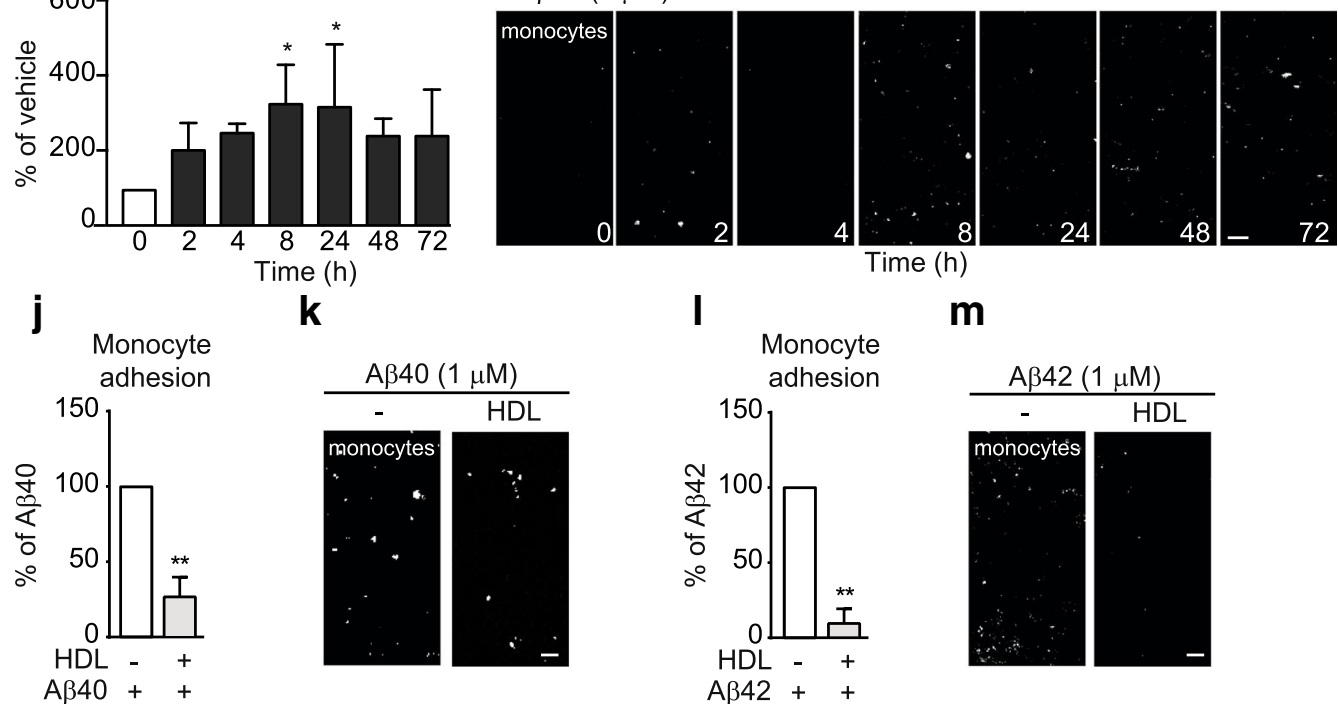

I

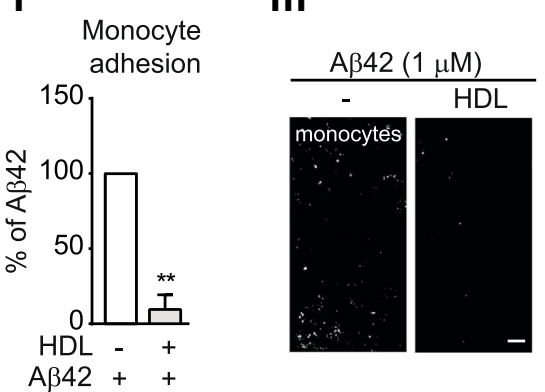

Fig. 1 (See legend on next page.) 


\section{(See figure on previous page.)}

Fig. $1 \mathrm{~A} \beta$ induces monocyte adhesion in engineered vessels, which is suppressed by HDL. a Schematic representation of bioengineered tissue. $\mathbf{b}$ Histological structure of engineered tissue using hematoxalin-eosin staining to reveal a dense tissue formation composed of cells and extracellular matrix in engineered vessels. $\mathbf{c}$ a-smooth muscle actin (a-SMA) confirmed the smooth muscle phenotype of cells in the inner layers and $\mathbf{d}$ CD31 confirmed an endothelial monolayer. Scale bar represents $200 \mu \mathrm{m}$. e Evans blue staining confirmed a tight endothelium. $\mathbf{f}-\mathbf{g} 1 \mu \mathrm{M}$ of A $\mathrm{A} 40$ or $\mathbf{h}-\mathbf{i}$ A 42 monomers were injected within the tissue chamber (abluminal). Fluorescently labeled human monocytes (THP1, white) were circulated in the lumen of the engineered vessels. Tissues were counterstained with DAPI (blue) and analyzed using confocal microscopy over time. j-m $200 \mu \mathrm{g} / \mathrm{mL}$ of $\mathrm{HDL}$ were circulated through the lumen of the grafts for $2 \mathrm{~h}$ prior injection of $1 \mu \mathrm{M}$ of $\mathbf{j}-\mathbf{k}$ A $\mathrm{B} 40$ or $\mathbf{I}-\mathbf{m}$ A 342 monomers within the tissue chamber (abluminal) for $8 \mathrm{~h}$ prior to circulating fluorescent THP1 in the lumen. Graphs represent means \pm SD of adhered monocytes relative to $A \beta$ treated tissues from at least 3 individual grafts. ${ }^{*} p<0.05,{ }^{* *} p<0.01$

The HFIP was removed by evaporation overnight. To prepare soluble monomers, the peptide film was reconstituted in DMSO to $5 \mathrm{mM}$, diluted further to $100 \mu \mathrm{M}$ in DMEM and used immediately. Oligomers were prepared by diluting the $5 \mathrm{mM}$ DMSO peptide solution in phenol red-free F12 medium (Life Technologies) to a final concentration of $100 \mu \mathrm{M}$ and incubating for $24 \mathrm{~h} 4{ }^{\circ} \mathrm{C}$. Fibrils were prepared by diluting the $5 \mathrm{mM}$ peptide solution in $0.1 \mathrm{uM}$ of $\mathrm{HCl}$ to a final concentration of $100 \mu \mathrm{M}$ and incubating for $24 \mathrm{~h}$ at $37{ }^{\circ} \mathrm{C}$. $\mathrm{A} \beta$ monomer, oligomer and fibril preparations were then either used to stimulate hCMEC/D3 monolayers, as given, or were analysed by Transmission Electron Microscopy (TEM) and dot blot. For TEM, $0.5 \mu \mathrm{L}$ of $100 \mu \mathrm{M}$ A $\beta$ preparation was diluted in $2 \mu \mathrm{L}$ filtered distilled water, spotted onto formvar-coated 200-mesh nickel grids (EM Sciences) and allowed to dry. Grids were then negatively stained with $0.5 \%$ aqueous uranyl acetate for $30 \mathrm{~s}$, and viewed on a FEI Tecnai G2 Spirit Transmission Electron Microscope. For dot blot, aliquots of $\mathrm{A} \beta(0.1 \mu \mathrm{M})$ were added to PVDF membrane, which were dried and blocked in $3 \%$ skimmed milk PBST. After $1 \mathrm{~h}$, blots were incubated with $\beta$-amyloid 1-16 antibody (6E10 Biolegend 1:500), amyloid A11 oligomeric antibody (AB9234 Millipore, 1:1000) or amyloid fibrils OC antibody (AB2286 Millipore, 1:1000) in blocking buffer for $16 \mathrm{~h}$, washed extensively in PBST and incubated with anti-mouse or anti-rabbit (1:1000) secondary antibody in blocking buffer. After $1 \mathrm{~h}$, blots were washed as above and developed using enhanced ECL and a ChemiDoc MP imager.

\section{Measurement of intracellular NO}

ECs were seeded at $5 \times 10^{5}$ cells/well in 6-well plates and cultured for 2 days until confluent in complete EBM-2. Sixteen hours before the assay, ECs were serumdepleted in EBM-2 containing 0.2\% FBS. On the day of the assay, ECs were incubated with $100 \mu \mathrm{g} / \mathrm{mL}$ of HDL in serum-depleted EBM-2 medium containing $1 \mu \mathrm{M}$ of 4,5-diaminofluorescein diacetate (DAF2, Caymanchem) at $37^{\circ} \mathrm{C}$. After $6 \mathrm{~h}$, ECs were washed with PBS, trypsinized, and triazolofluorescein fluorescence was measured (excitation wavelength of $485 \mathrm{~nm}$, emission $538 \mathrm{~nm})$, using an Infinite M200Pro plate reader (Tecan). In addition to DAF2 measurement, the phosphorylation of eNOS at Ser1177 was compared to total
eNOS by immunoblotting (below) in cell lysates harvested $15 \mathrm{~min}$ after HDL treatment.

\section{Cell surface biotinylation}

ECs were seeded at $5 \times 10^{5}$ cells/well in 6-well plates and cultured for 2 days until confluent. On the day of the assay, ECs were treated with HDL, A $\beta$ or TNF- $\alpha$ as above. After stimulation, EC monolayers were washed twice with ice cold PBS ( $\mathrm{pH} 8$ ), cooled on ice for $15 \mathrm{~min}$ and biotinylated with $250 \mu \mathrm{g} / \mathrm{mL}$ EZ-link ${ }^{\mathrm{TN}}$-sulfo-NHSbiotin (ThermoFisher Scientific) in PBS (pH 8) at $4{ }^{\circ} \mathrm{C}$. After $1 \mathrm{~h}$ the reaction was stopped with a $5 \mathrm{~min}$ incubation in DMEM with 10\% FBS. After two additional PBS washes, ECs were lysed in RIPA buffer. Following quantification of protein concentration using a BCA assay (Thermofisher Scientific), at least $100 \mu \mathrm{g}$ of protein were incubated with streptavidin-conjugated sepharose beads (Pierce) at $4{ }^{\circ} \mathrm{C}$ overnight. Beads were washed 3 times with RIPA buffer and the recovered proteins were resolved on a SDS-PAGE.

\section{Monolayer $\mathrm{a} \beta$ association, binding and uptake}

ECs were seeded at $3 \times 10^{5}$ cells/well in 12 -well plates and cultured until confluent for 2 to 3 days. On the day of the assay, ECs were primed for $2 \mathrm{~h}$ with $100 \mu \mathrm{g} / \mathrm{mL}$ HDL before stimulating with $0.1 \mu \mathrm{M}$ of $\mathrm{A} \beta 40$ and $\mathrm{A} \beta 42$ monomers at $37{ }^{\circ} \mathrm{C}$ for total association, or at $4{ }^{\circ} \mathrm{C}$ for cell surface binding. After $3 \mathrm{~h}, \mathrm{hCMEC} / \mathrm{D} 3$ were washed 3 times with $\mathrm{PBC}$ and lysed in RIPA buffer containing $10 \mathrm{mM}$ Tris $\mathrm{pH} 7.4,150 \mathrm{mM} \mathrm{NaCl}, 1.0 \% \mathrm{NP}-40$, 1.0 '."\% sodium deoxycholate, $0.1 \%$ SDS and cOmplete protease inhibitor with EDTA (Roche). A 340 (KHB3442, Life Tech) and A 342 (KHB3482, Life Tech) were quantified using commercial ELISAs and normalized to total protein concentration. For A $\beta$ uptake, hCMEC/D3 were seeded at $1 \times 10^{5}$ cells/well in 24-well plates and cultured to confluence for 2 to 3 days. On the day of the assay endothelial, ECs were primed for $2 \mathrm{~h}$ with $1 \mathrm{mg} / \mathrm{mL}$ of HDL before stimulating with $1 \mu \mathrm{M}$ monomeric FITC$\mathrm{A} \beta 40$ and FITC-A $\beta 42$ (Bachem) prepared as described above. After $3 \mathrm{~h}$ at $37{ }^{\circ} \mathrm{C}, \mathrm{hCMEC} / \mathrm{D} 3$ were washed 3 times with PBS and fixed in 4\% PFA for $20 \mathrm{~min}$. After one Tris- $\mathrm{HCl}$ and two PBS washes, hCMEC/D3 were mounted in Prolong antifade reagent. 


\section{Molecular biology}

For mRNA, cells were lysed in Trizol (Invitrogen) and RNA was extracted and treated with DNase I (Invitrogen) according to the manufacturer's protocol. cDNA was generated using oligo-dT primers and Taqman reverse transcription reagents (Applied Biosystems). Real-time quantitative PCR was done using FastStart Universal SYBR Green Master reagent (Roche) on a Light Cycler 96 system (Roche) to quantify gene expression relative to vehicle using specific primer against ICAM-1 (fwd: ATGGCAACGAC TCCTTCTCG; rev: CGCCGGAAAGCTGTAGATGG) and VCAM-1 (fwd: TGTTTGCAGCTTCTCAAGCTTTT; rev: GATGTGGTCCCCTCATTCGT) and normalized to GAPDH (fwd: CCTGCACCACCAACTGCTTA; rev: CATGAGTCCTTCCACGATACCA). MiRNA was isolated using an miRNeasy mini kit (Qiagen) following the manufacturer's instructions, respectively. Reverse transcription was performed using $2 \mu \mathrm{g}$ of total RNA with specific miRNA primers (Life Technology). MiR223 and U6 were quantified using specific TaqMan probes (Life Technology).

\section{Immunoblot}

ECs were lysed in RIPA buffer containing either cOmplete protease inhibitor or Phosphostop (Roche) and quantified using a BCA assay. Equal amounts of total protein were separated by SDS-PAGE followed by electrophoretic transfer to polyvinylidene fluoride (PVDF) membranes (Millipore). After blocking membranes for $1 \mathrm{~h}$ with $5 \%$ skim milk powder in PBST, or 5\% BSA in TBST for phosphoproteins, ICAM-1, (EP1442Y Abcam, 1:1000), VCAM-1 (EPR5047 Novus, 1:1000), peNOS (ser1177 Cellsignalling, 1:1000), eNOS (M221 ABCAM, 1:1000), AnxA1 (D5V2T, Cellsignalling, 1:1000), p-Akt (Ser473 D9E, Cellsignalling, 1:2000), Akt (9272, Cellsignalling, 1:1000), p-NF-kB p65 (Ser536 93H1, Cellsignalling, 1:1000), NF-kB p65 (D14E12, Cellsignalling, 1:1000), p-SAPK/JNK (Thr183/Tyr185 G9, Cellsignalling, 1:1000), JNK (2C6, Cellsignalling, 1:1000), p-p42/44 MAPK (Erk1/2) (Thr202/Tyr204 D13.14.4E, Cellsignalling, 1:1000), p42/44 MAPK (Erk1/2) (137F5, Cellsignalling, 1:1000), p-Stat3 (Tyr705, Cellsignalling 1:1000), Stat3 (124H6, Cellsignalling, 1:1000) and GAPDH (MAB374 1:10,000, Millipore) were immunodetected by incubating for $16 \mathrm{~h}$ in primary antibody in blocking buffers. Membranes were washed extensively with PBST or TBST, and incubated with anti-mouse or anti-rabbit (1:1000-10'000, Jackson ImmunoResearch) secondary antibody in blocking buffer. After $1 \mathrm{~h}$, membranes were washed as above and developed using enhanced chemiluminescence (ECL, Amersham) and a ChemiDoc MP imager (Biorad). Densitometric images were captured with ImageJ and band intensity normalized to GAPDH as a loading control.

\section{Beta-sheet formation assay}

Cell-free Thioflavin-T fibrillization assays were performed on an Infinite M2000 Pro plate reader (Tecan) as described (Truran 2015). Briefly, $10 \mu \mathrm{M}$ monomeric $A \beta 40$ or $A \beta 42$ were incubated in a buffer consisting of $20 \mathrm{mM}$ of Thioflavin- $\mathrm{T}$ in $150 \mathrm{mM} \mathrm{NaCl}$ and $5 \mu \mathrm{M}$ of HEPES at $\mathrm{pH} 7.4$, with and without $1 \mathrm{mg} / \mathrm{mL}$ of HDL, at $37{ }^{\circ} \mathrm{C}$ with $20 \mathrm{~s}$ of orbital shaking ( $3 \mathrm{~mm}$ amplitude) every 5 min in a black 96-well plate. Formation of fibrillar $\beta$-amyloid pleated sheets over time was monitored by excitation at $440 \mathrm{~nm}$ and measuring emission intensity at $490 \mathrm{~nm}$ every $5 \mathrm{~min}$ up to $12 \mathrm{~h}$ in total.

\section{Human brain protein extraction and ELISA}

Frozen brain tissues (cortex Brodmann area 9 and cerebellum) were provided by the Harvard Brain Tissue Resource Center under an approved UBC protocol (C04-0595) and extracted with 8 volumes of ice-cold carbonate buffer (100 mM Na $\mathrm{CO}_{3}, 50 \mathrm{mM} \mathrm{NaCl}, \mathrm{pH}$ 11.5) containing cOmplete protease inhibitor (Roche Applied Science) by manual homogenization with a tissue probe. After incubating on ice for $10 \mathrm{~min}$, lysates were clarified by centrifugation at $16,600 \mathrm{rcf}$ for $45 \mathrm{~min}$ at $4{ }^{\circ} \mathrm{C}$. The supernatant was removed and neutralized by adding 1.5-volumes of $1 \mathrm{M}$ Tris- $\mathrm{HCl} \mathrm{pH} 6.8$ to give a final $\mathrm{pH}$ of approximately 7.4. Brain tissues from all samples were extracted in an identical manner, and fractions were aliquoted and immediately frozen at $-80{ }^{\circ} \mathrm{C}$ until analysis. Protein concentrations were determined using the Lowry Protein Assay (Biorad). ICAM-1 (ab174445, ABCAM), VCAM-1 (ab187393, ABCAM), Aß40 (KHB3442, Life Tech) and A 342 (KHB3482, Life Tech) in carbonate extracts were quantified using commercial ELISAs. ELISA data were normalized to total protein concentration of the extract. For immunofluorescent staining, brains were sectioned at $20 \mu \mathrm{m}$, rehydrated in PBS and blocked in 4\% paraformaldehyde (PFA). After $20 \mathrm{~min}$, sections were washed once with Tris- $\mathrm{HCl}(0.5 \mathrm{mM}, \mathrm{pH}$ 8), twice with $\mathrm{PBS}$, and blocked in blocking buffer (5\% goat serum and $1 \%$ BSA). After $60 \mathrm{~min}$, section were incubated at $4{ }^{\circ} \mathrm{C}$ with antibodies against CD31 (WM59 Biolegend, 1:50), ICAM-1 (EP1442Y ABCAM 1:200), and VCAM-1 (EPR5047 ABCAM 1:200) in blocking buffer overnight. Sections were washed 3 times in PBS and incubated at RT with Alexa-488 anti-mouse and Alexa-594 anti-rabbit fluorescently labeled secondary antibodies (LifeTechnologies, 1:600). After $45 \mathrm{~min}$ and 3 additional PBS washes, sections were mounted in Prolong Gold antifade reagent with DAPI (LifeTechnologies) and imaged on an inverted fluorescent microscope (Zeiss)

\section{Statistical analysis}

All statistical analyses were performed using SPSS and $p$-values $<0.05$ were considered significant. Data were 
obtained from at least 3 independent experiments and are presented as mean \pm SD if not indicated otherwise. Data were first log transformed and analyzed by twoway ANOVA with a blocking factor (experiment) with direct comparison when comparing two treatments or Dunnett's or Bonferonni multi-comparison tests. After statistical calculations, vehicle data were normalized to $100 \%$ and represented as a dashed line in the graph, and tested conditions were expressed and graphed as percentage of vehicle if not otherwise stated.

\section{Results}

HDL suppresses a $\beta$-mediated monocyte adhesion to ECs in three-dimensional dynamic engineered human vessels

To mimic the complexity of native cell-cell and/or cellmatrix interactions observed in native human vessels, we used innovative tissue engineering technology to generate in vitro 3D human vessels composed of primary human umbilical vein ECs (HUVEC) and primary human smooth muscle cells (SMC) to maximize translational relevance of our studies relative to in vitro studies that solely use traditional static cell culture models. Our system uses a scaffold-directed dynamic, semi-pulsatile flow bioreactor system, on which primary human cells are sequentially seeded into $2 \mathrm{~mm}$ diameter biodegradable polyglycolicacid (PGA)/polycaprolactone (PCL) composite matrices. After a short static incubation, vascular constructs are exposed to dynamic flow in a bioreactor, where nutrient medium is directed through the lumen of the bioreactor circulation loop to mimic native blood flow. We previously demonstrated that these scaffold-directed engineered vessels are useful for studies of endothelial activation in 3D culture [17]. A schematic of the bioreactor system is presented in Fig. 1a. Under our flow bioreactor conditions, haematoxylin and eosin staining confirmed a dense tissue formation composed of cells with extracellular matrix on the luminal side of the scaffold (Fig. 1b-d). Immunofluorescent staining confirmed a SMC phenotype of cells in the inner layers and an EC monolayer on the luminal side (Fig. 1c,d). Integrity of the endothelial barrier was functionally assessed by injecting Evans blue dye into the bioreactor circulation loop, which was excluded after EC seeding, demonstrating a functionally tight endothelial barrier (Fig. 1e).

Having established a 3D human vascular model, we injected $1 \mu \mathrm{M} A \beta 40$ or $A \beta 42$ directly into the graft chamber to mimic $A \beta$ coming from the brain anteluminal side, followed by injection of human THP-1 monocytes into the lumen chamber to mimic circulating monocytes. Both $A \beta 40$ and $A \beta 42$ led to THP1 adhesion to endothelium in the engineered vessels, with the most robust response appearing $8 \mathrm{~h}$ after $\mathrm{A} \beta$ injection (Fig. 1f-h). We then tested the ability of HDL, isolated from healthy human donors using $\mathrm{KBr}$ density gradient ultracentrifugation, to suppress
A $\beta$-induced monocyte adhesion to ECs in engineered vessels by circulating either media alone or $200 \mu \mathrm{g} / \mathrm{mL}$ of HDL for $2 \mathrm{~h}$ prior to injecting $1 \mu \mathrm{M} \mathrm{A} \beta$ into the graft chamber. In this engineered vascular model, HDL robustly suppressed monocyte adhesion to endothelium by both A 340 (5 fold, $p=0.0286$ ) and A $\beta 42$ (10 fold, $p=0.0016$ ) (Fig. 1i-l).

\section{HDL attenuates a $\beta$-induced peripheral blood mono- nuclear cell (PBMC) adhesion in monotypic ECs}

To define the mechanisms by which HDL attenuates A $\beta$-induced monocyte binding to ECs, we used static monolayer EC cultures and peripheral blood mononuclear cells (PBMC) isolated by continuous density gradient ultracentrifugation from healthy human donors. We first confirmed that $A \beta$ induces PBMC adhesion in monotypic HUVEC cultures and that HDL attenuates this activity (Fig. 2a,b). As $A \beta$ originates within the brain and the primary pathways by which $A \beta$ is cleared from the brain involve cerebral vessels [7], we also showed that the human brain microvascular endothelial cell line hCMEC/ D3, a commonly used cell line for in vitro studies of the blood brain barrier (BBB) [20], also exhibit increased PBMC adhesion upon $A \beta$ treatment and that this too is attenuated by HDL (Fig. 2c,d). As HUVEC and hCMEC/D3 give nearly identical results, we focused on hCMEC/D3 cells for all subsequent mechanistic experiments.

Our first question was to determine if lipid-free apoA-I was functionally equivalent to mature $\mathrm{HDL}$ in its ability to suppress $\mathrm{A} \beta$-mediated PBMC binding to hCMEC/D3. Our results clearly showed that pre-incubation of hCMEC/D3 with lipid-free apoA-I (50 and $100 \mu \mathrm{g} / \mathrm{mL}$ ) did not alter $\mathrm{A} \beta$-induced PBMC adhesion (Fig. 2e,f), demonstrating that mature HDL particles are required to attenuate $\mathrm{A} \beta$ induced PBMC adhesion to brain-derived ECs.

To establish the experimental conditions to investigate how HDL suppresses $A \beta$-mediated PBMC adhesion to hCMEC/D3, we performed PMBC adhesion assays in hCMEC/D3 after a $3 \mathrm{~h}$ exposure to increasing concentrations human $A \beta 40$ and $A \beta 42$ monomers. Compared to baseline, $\mathrm{A} \beta 40$ concentrations of $0.01,0.1$ and $1.0 \mu \mathrm{M}$ led to significant $175 \%, 169 \%$ and $179 \%$ increases in PMBC adhesion $(p=0.033,0.002$ and 0.019 respectively, Additional file 1a), The same concentrations of $\mathrm{A} \beta 42$ also led to significant $184 \%, 161 \%$ and $223 \%$ increases in PMBC adhesion ( $p=0.019,0.0406$ and 0.0421 , respectively) relative to baseline (Additional file 1b). Having demonstrated that $0.1 \mu \mathrm{M}$ of monomeric $\mathrm{A} \beta 40$ or $\mathrm{A} \beta 42$ is sufficient to induce PMBC adhesion in hCMEC/D3, we then tested whether pre-treating hCMEC/D3 for $2 \mathrm{~h}$ with 0 to $400 \mu \mathrm{g} / \mathrm{mL}$ HDL could attenuate $\mathrm{A} \beta$-induced PBMC adhesion. Significant suppression of PBMC adhesion was observed at concentrations of HDL from $100 \mu \mathrm{g} / \mathrm{mL}$ and above. At $100 \mu \mathrm{g} / \mathrm{mL}$ HDL there was an 


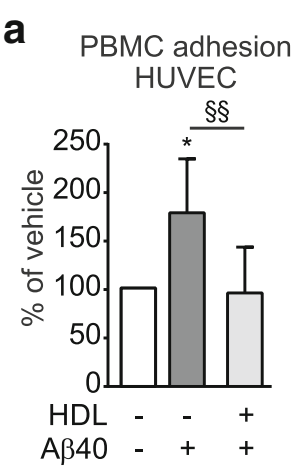

C
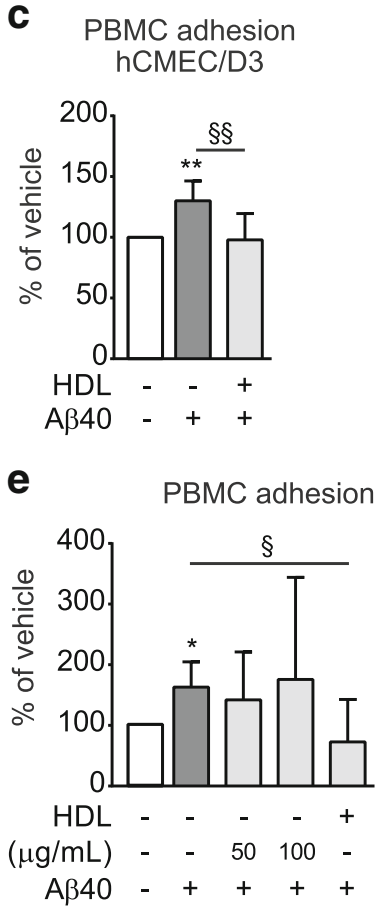

b

PBMC adhesion

HUVEC

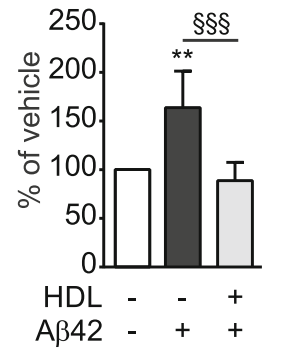

d PBMC adhesion hCMEC/D3

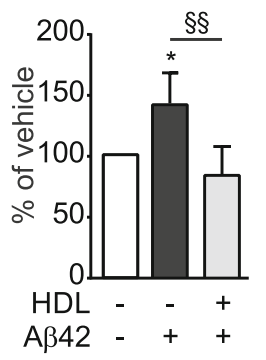

f

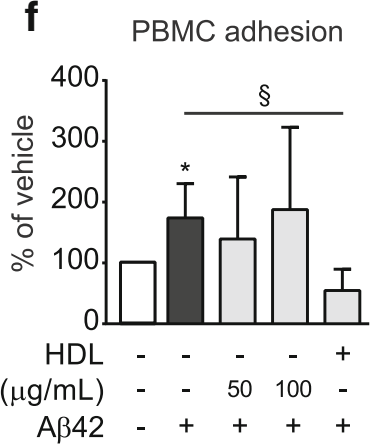

Fig. $2 A \beta 40$ and $A B 42$ induce PBMC adhesion to ECs, which is suppressed by HDL. HUVEC (a-b) or hCMEC/D3 (c-d) were primed with $100 \mu \mathrm{g} /$ $\mathrm{mL}$ of $\mathrm{HDL}$ and stimulated with $0.1 \mu \mathrm{M} \mathbf{a}, \mathbf{c} A \beta 40$ (light grey) or $\mathbf{b}, \mathbf{d A} \beta 42$ (dark grey) monomers for $3 \mathrm{~h}$. Fluorescently labelled PBMC were allowed to adhere to stimulated cells for $3 \mathrm{~h}$ followed by washing, fixation, imaging, and counting. hCMEC/D3 were primed with either $100 \mu \mathrm{g} /$

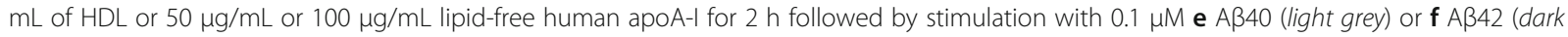
grey) monomers for $3 \mathrm{~h}$. Cells were washed, imaged and counted as above. Graphs represent mean \pm SD of adhered PBMC relative to vehicle control from at least 3 independent trials where ${ }^{*} p<0.05,{ }^{* *} p<0.01,{ }^{* * *} p<0.001$ versus vehicle, $\S p<0.05, \S \S p<0.01$ versus A $\beta$

$80 \%$ and $60 \%$ reduction of adhered PBMCs in cells induced by $0.1 \mu \mathrm{M} \mathrm{A} \beta 40(p=0.017)$ or $0.1 \mu \mathrm{M} \mathrm{A} \beta 42$ $(p=0.018)$ respectively (Additional file $1 \mathrm{c}, \mathrm{d})$.

\section{$H D L$ reduces the fibrillization rate of $a \beta 42$ and $a \beta 40$ in cell-free conditions}

As $A \beta$ has been reported to bind HDL-like particles in both cerebrospinal fluid (CSF) and blood [21], and apoA-I has been reported to affect $A \beta$ aggregation [13, 22], we reasoned that one mechanism by which HDL may attenuate PBMC adhesion to hCMEC/D3 could be by affecting $A \beta$ structure to prevent the formation of toxic higher order species [23]. A cell-free Thioflavin-T reporter assay was used to determine whether HDL affects the fibrillization kinetics of $A \beta 40$ or $A \beta 42$ over a $12 \mathrm{~h}$ period, using $10 \mu \mathrm{M} \mathrm{A} \beta$ and $10 \mathrm{mg} / \mathrm{mL}$ HDL (ratio: $1: 1$ ), which is the same $A \beta: H D L$ ratio used for our cellular PBMC adhesion assays and allows detection of fluorescence signal using a plate reader (Fig. 2c,d). Under these conditions, in the absence of $\mathrm{HDL}$, the onset of $\mathrm{A} \beta$ fibrillization requires at least $3 \mathrm{~h}$ for $\mathrm{A} \beta 42$ and at least $10 \mathrm{~h}$ for $\mathrm{A} \beta 40$. Notably, in the presence of HDL, we observed delayed onset of fibrillization for both $A \beta 42$ and $A \beta 40$, and a slower rate of $A \beta 42$ fibrillization (Fig. 3a). As HDL can suppress PBMC 
a

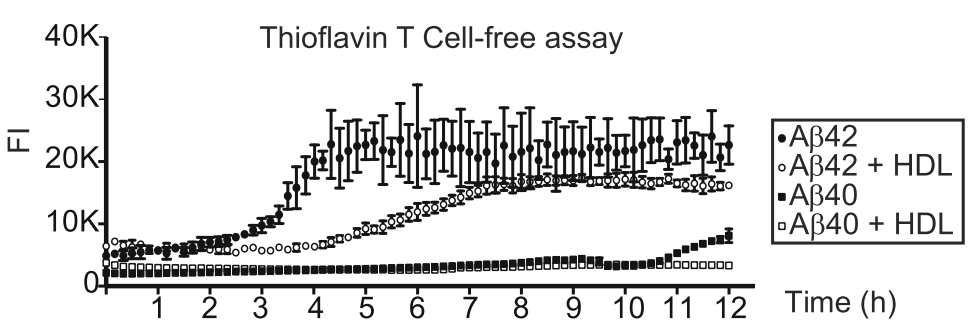

b

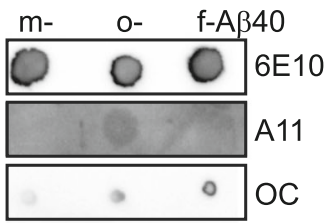

d

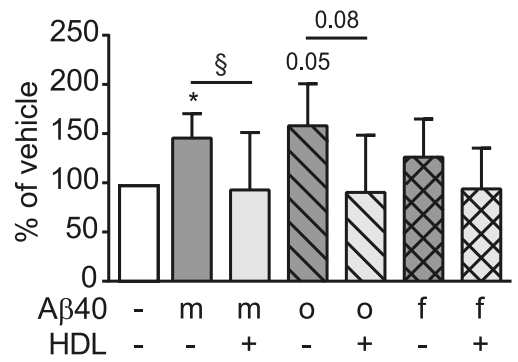

f

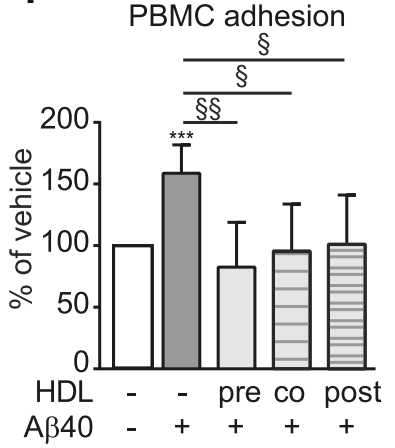

C

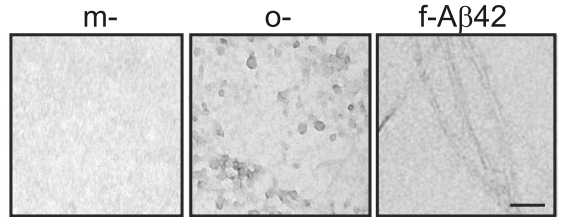

e

PBMC adhesion

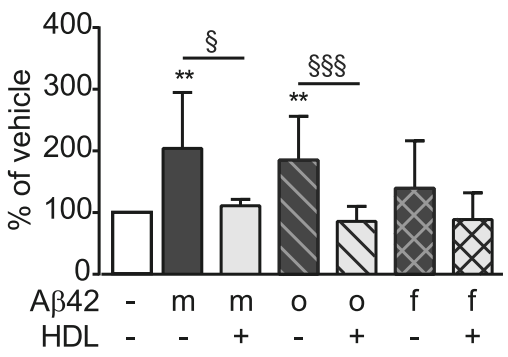

g

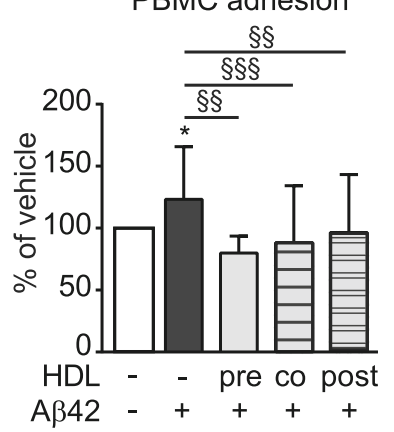

Fig. $3 \mathrm{HDL}$ delays beta-sheet formation and attenuates $A \beta$-induced PBMC adherence independent of $A \beta$ structure. a Representative graph $\pm S D$ of technical triplicates of 3 individual experiments where $10 \mu \mathrm{M} \mathrm{A \beta 40}$ or $\mathrm{A} \beta 42$ with or without $10 \mathrm{mg} / \mathrm{mLI} \mathrm{HDL}$ were incubated with $20 \mu \mathrm{M}$ of Thio- $\mathrm{T}$ in $150 \mathrm{mM} \mathrm{NaCl}$ and $5 \mu \mathrm{M}$ of HEPES (pH 7.4) for $12 \mathrm{~h}$ at $37^{\circ} \mathrm{C}$. Formation of $\beta$-amyloid pleated sheets was monitored every 5 min at excitation $440 \mathrm{~nm}$ and emission $490 \mathrm{~nm}$. b-c $A \beta$ structures were confirmed using dot blot with antibodies against oligomers (A11) or fibrils (OC) and electron microscopy (EM). d-e hCMEC/D3 were stimulated for $3 \mathrm{~h}$ with $0.1 \mu \mathrm{M}$ monomeric ( $\mathrm{m}$-A $\beta$, solid bar), oligomeric (o-A $\beta$, striped bar) or fibrillar-aggregated (f-A A $\beta$, cross-hatched bar) $\mathbf{d} A \beta 40$ or e $A \beta 42$ in the presence or absence of HDL. $\mathbf{f}-\mathbf{g}$ hCMEC/D3 were pre-incubated for $2 \mathrm{~h}$ with $100 \mu \mathrm{g} / \mathrm{mL} \mathrm{HDL}$ prior to $A \beta$ addition (pre, solid bar), co-incubated with $100 \mu \mathrm{g} / \mathrm{mL} \mathrm{HDL}$ and $A \beta$ (co, striped bar), or post-incubated by adding $100 \mathrm{\mu g} / \mathrm{mL} \mathrm{HDL} 1 \mathrm{~h}$ following A $\beta$ stimulation (post, double striped bar). Graphs represent means \pm SD of adhered PBMC relative to vehicle treated cells from at least 5 independent trials where. ${ }^{*} p<0.05,{ }^{* *} p<0.01,{ }^{* * *} p<0.001{ }^{*} p<0.05,{ }^{* *} p<0.01,{ }^{* * *} p<0.001$ versus vehicle, $\S p<0.05, \S \S$ $p<0.01, \S \S \S p<0.001$ versus $A \beta$

adhesion to hCMEC/D3 induced by both $\mathrm{A} \beta 40$ and $\mathrm{A} \beta 42$ within $3 \mathrm{~h}$ of $\mathrm{A} \beta$ addition, we conclude that suppression of $A \beta$ fibrillization cannot be the only mechanism by which HDL functions to protect ECs from the detrimental effects of $A \beta$.
$A \beta$ structure does not affect HDL's ability to reduce PBMC adhesion to hCMEC/D3

Several experiments were then performed to further test whether $A \beta$ structure affects HDL's anti-inflammatory activity on hCMEC/D3. We varied the structural species 
of the $\mathrm{A} \beta$ preparation added to $\mathrm{hCMEC/D3}$, reasoning that if HDL acts primarily through maintaining $A \beta$ in a soluble monomeric state, the protective effect of HDL should be diminished if ECs are stimulated with preformed $A \beta$ oligomers or fibrils. Soluble monomeric and oligomeric, and insoluble fibrillar $A \beta$ were prepared as described [24] and structures were confirmed using a dot blot assay as well as electron microscopy (Fig. 3b,c). Interestingly, monomeric and oligomeric $A \beta 40$ and A $\beta 42$ preparations induced comparably robust PBMC adherence, whereas the insoluble fibrillary form failed to significantly increase PBMC adhesion. Importantly, the ability of HDL to suppress PMBC adhesion was unaffected by input of either $A \beta$ monomers or oligomers (Fig. 3d-e). These results suggest that delayed $A \beta$ fibrillization may not be the major pathway by which HDL suppresses PBMC adhesion to ECs under our experimental conditions as HDL maintained its protective effect when ECs are treated with pre-formed oligomers. To confirm this, we also varied the timing of HDL and $\mathrm{A} \beta$ addition to hCMEC/D3 such that, in addition to a $2 \mathrm{~h}$ HDL pre-incubation as above, HDL was added at the same time as $A \beta$ (co-incubation) or $1 \mathrm{~h}$ after $A \beta$ addition (post-incubation). We reasoned that if HDL acts primarily through maintaining $A \beta$ solubility, preincubation and co-incubation designs should give equivalent and maximal suppression of $A \beta$-induced PBMC adhesion as, in both scenarios, $A \beta$ is always in the presence of HDL and aggregation could be delayed. In contrast, as the post-incubation scenario would allow $A \beta$ aggregation to begin prior to addition of HDL, the protective effect of HDL should be reduced if added after the $A \beta$ stimulus if $A \beta$ structure is the key driver of PBMC adhesion to ECs. We observed that PMBC adhesion was significantly and similarly reduced regardless of when HDL was added to hCMEC/D3 relative to A $\beta 40$ or A $\beta 42$ providing additional support that HDL's ability to attenuate $\mathrm{A} \beta$-mediated $\mathrm{PBMC}$ adhesion to hCMEC/ $D 3$ is independent of whether $A \beta$ input is monomeric or oligomeric (Fig. 3f,g).

These two lines of evidence suggest that, although HDL can affect $A \beta$ structure in cell-free conditions, these effects are neither rapid nor robust enough to fully explain how HDL suppresses $A \beta$ mediated PBMC adhesion to hCMEC/D3. We next evaluated signalling pathways implicated in HDL's anti-inflammatory effects on ECs.

\section{The ability of HDL to suppresses a $\beta$-induced PBMC adhesion to $h C M E C / D 3$ is independent of nitric oxide (NO) production and Annexin A1 (Anx1)}

Stimulation of NO synthesis by HDL is reported to reduce arterial EC activation [25]. We therefore tested whether HDL induces NO production in hCMEC/D3 using the cell permeable indicator 4,5-Diaminofluorescein diacetate
(DAF2), which reacts with NO to produce highly fluorescent trizaolo-fluorescein. Compared to baseline conditions, HDL-treated hCMEC/D3 showed a significant 130\% increase $(p=0.01)$ in NO production (Fig. 4a), as well as significantly elevated phosphorylated endothelial NO synthase (eNOS) on serine $1177(161 \%, p=0.047)$ (Fig. 4b,c). These results confirm that HDL can induce NO production in hCMEC/D3, as observed in ECs derived from other origins.

To test whether NO generation is required for HDL to suppress $\mathrm{A} \beta$-mediated PBMC adhesion to hCMEC/D3, we treated cells with the eNOS inhibitor L-NAME, followed by the addition of HDL, and finally stimulation with either $A \beta 40, A \beta 42$ or TNF- $\alpha$. We observed that blocking eNOS with L-NAME had no effect on the ability of HDL to suppress either A $\beta$ - or TNF- $\alpha$-mediated PBMC adhesion to hCMEC/D3 (Fig. 4d-f). Additional experiments confirmed the potency of L-NAME to block eNOS in HDL-stimulated HUVEC (Additional file 2a), yet this also had no effect on the ability of HDL to suppress either A $\beta$ - or TNF- $\alpha$ - mediated PBMC binding in HUVEC (Additional file $2 \mathrm{~b}-\mathrm{d}$ ). We further ruled out a role for the NO pathway in hCMEC/D3 by measuring the effect of HDL in the presence of VPC23019, an antagonist of sphingosine-1 phosphate receptor 1 (S1P1) and S1P3, receptors that are required for eNOS activity [26], and again found no effect on the ability of HDL to suppress either A $\beta$ - or TNF- $\alpha$-mediated PBMC adhesion to hCMEC/D3 (Fig. 4g-i) or HUVEC (Additional file $2 \mathrm{e}-\mathrm{h}$ ). Taken together, these results provide strong support that the eNOS pathway is not involved in the ability of HDL to suppress PBMC adhesion to $A \beta$ - or TNF- $\alpha$-activated hCMEC/D3 and HUVEC.

In contrast to a recent report suggesting that HDL upregulates Anx1, which affects HDL's ability to suppress ECs activation [27], we observed no significant change in Anx1 protein levels in hCMEC/D3 after either HDL or $\mathrm{A} \beta$ treatment (Additional file $2 \mathrm{i}$ ).

\section{HDL-mediated suppression of a $\beta$-induced PBMC adhesion to $\mathrm{hCMEC/D3}$ is independent of miR-233}

In addition to numerous proteins and lipid species, HDL particles carry microRNAs (miRNAs) that can correlate with vascular disease risk [28]. One of the most abundant miRNAs in HDL is miR-233, which has recently been shown to affect gene expression in human coronary artery ECs including suppressing ICAM-1 expression [29]. Three lines of evidence suggest that HDL-mediated suppression of $\mathrm{A} \beta$-mediated PBMC binding to hCMEC/D3 is independent of miR-233. First, direct transfection of a miR-223 mimetic did not prevent $A \beta 40$ or TNF- $\alpha$-mediated PBMC adhesion to hCMEC/D3, although a statistically significant reduction with $\mathrm{A} \beta 42$ was observed (Additional file $3 \mathrm{a}-\mathrm{C}$ ). Second, priming hCMEC/D3 with HDL in the presence of 

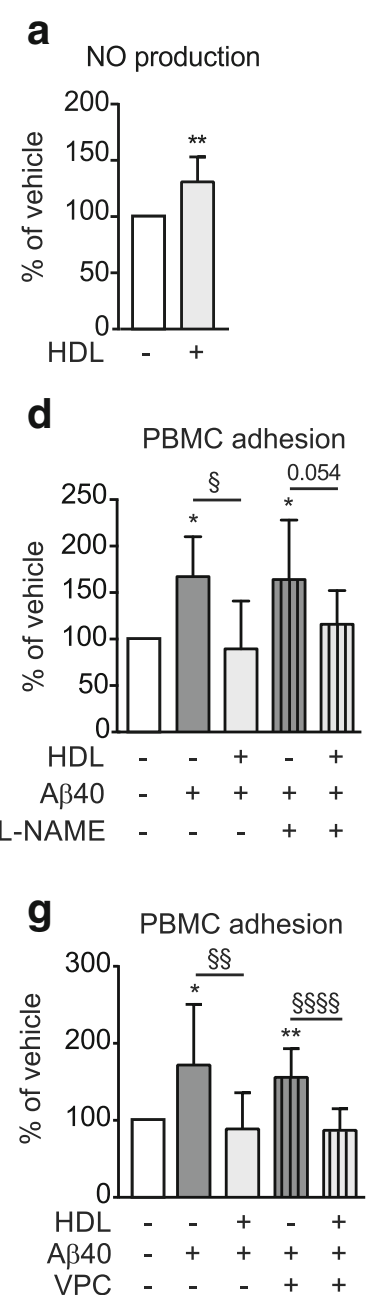
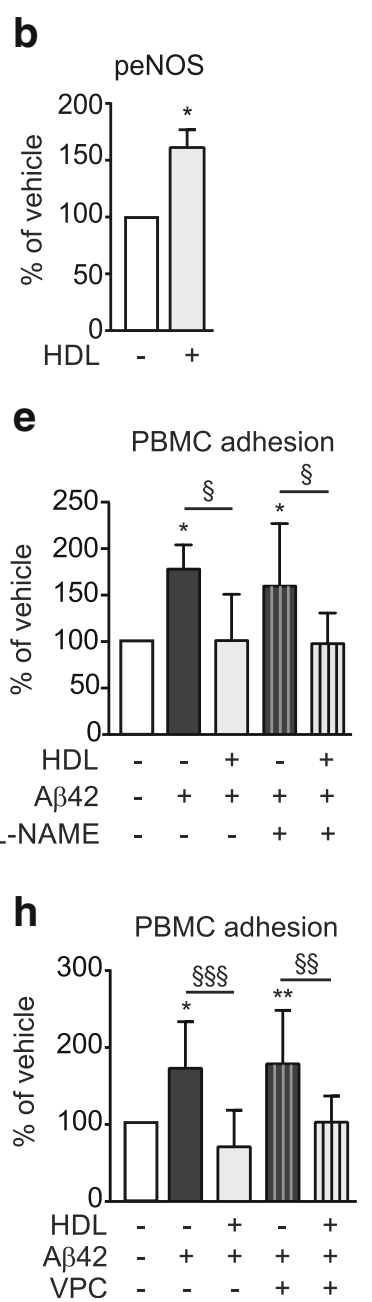

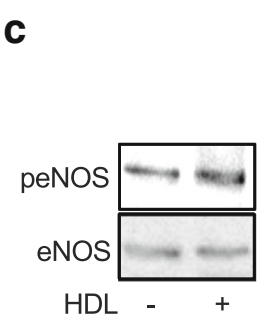

\section{f}
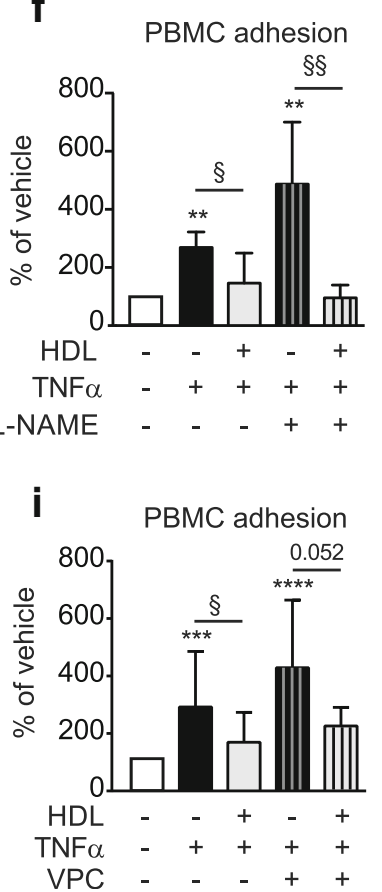

Fig. $4 \mathrm{HDL}$ suppression of Aß-induced inflammation is independent of eNOS and S1P. a Intracellular NO production was measured by treating hCMEC/D3 with $100 \mu \mathrm{g} / \mathrm{mL} \mathrm{HDL}$ in the presence of $1 \mu \mathrm{M}$ DAF-2 for $6 \mathrm{~h}$. Fluorescence was measured at $485 \mathrm{~nm}$. $\mathbf{b}$ Phosphorylation of eNOS was measured by treating hCMEC/D3 with $100 \mu \mathrm{g} / \mathrm{mL}$ HDL for 15 min before immunoblotting for phosphorylated eNOS (p-eNOS) or total eNOS. Representative immunoblots are shown in (c). hCMEC/D3 were pretreated for $1 \mathrm{~h}$ with the eNOS inhibitor L-NAME (d-f) or the S1P1 and S1P3 inhibitor VPC23019 (g-i) followed by $100 \mu \mathrm{g} / \mathrm{mL}$ HDL for $2 \mathrm{~h}$. Cells were then stimulated with $0.1 \mu \mathrm{M}$ Aß40 (d,g) A 42 monomers, (e,h) or $1 \mathrm{ng} / \mathrm{mL}$ of TNF-a (f,i) for $3 \mathrm{~h}$ before testing PBMC adherence. Graphs represent means \pm SD of adhered PBMC relative to vehicle treated cells for at least 5 independent trials. ${ }^{*} p<0.05,{ }^{* *} p<0.01,{ }^{* * *} p<0.001{ }^{*} p<0.05,{ }^{* *} p<0.01,{ }^{* * *} p<0.001$ versus vehicle, $\S p<0.05, \S \S p<0.01, \S \S \S p<0.001$ versus A $\beta$ or TNF-a

a specific miR-223 inhibitor did not diminish the ability of HDL to suppress PMBC adhesion by $\mathrm{A} \beta 40$, A $\beta 42$ or TNF$\alpha$ (Additional file $3 \mathrm{~d}-\mathrm{f}$ ). Third, in the $5 \mathrm{~h}$ period where hCMEC/D3 were exposed to HDL ( $2 \mathrm{~h}$ pre-treatment then $3 \mathrm{~h}$ with $\mathrm{A} \beta$ ), no significant transfer of miR-223 was detected (see Additional file $3 \mathrm{~g}$ ), consistent with a previous report that after $6 \mathrm{~h}$, miR-223 was not transferred from HDL to several types of ECs including HUVEC [30]. These results suggest that, although the miR-233 mimetic can suppress A 342 -mediated PBMC binding to hCMEC/D3 when added directly, miR-233 is unlikely to underlie the ability of HDL to suppress PBMC adhesion to hCMEC/D3 triggered by $\mathrm{A} \beta 40, \mathrm{~A} \beta 42$ or TNF- $\alpha$.
HDL-mediated suppression of a $\beta$-induced PBMC adhesion to hCMEC/D3 is independent of ICAM-1 and VCAM-1.

ICAM-1 and VCAM-1 are canonical markers of EC activation that mediate PBMC adhesion by classical inflammatory stimuli [31]. Several studies have reported elevated microvascular inflammatory markers in the $\mathrm{AD}$ brain [32, 33]. Using ELISA, we confirmed that protein levels of intercellular adhesion molecule 1 (ICAM-1) but not vascular cell adhesion molecule 1 (VCAM-1) are increased in the cortex of $\mathrm{AD}$ patients compared to either cerebellum from the same individual or the cortex from non-cognitively impaired (NCI) control subjects (Additional file 4). Increased ICAM1 levels were further confirmed using immunofluorescence 
revealing both vascular and glial ICAM-1 reactivity whereas VCAM-1 remained unchanged (Additional file $5 a-b$ ). As expected, soluble $A \beta 40$ and $A \beta 42$ levels were elevated in the cortex of $\mathrm{AD}$ patients compared to their corresponding cerebellum or to the cortex of NCI subjects (Additional file 4). Because ICAM-1 is a classical marker of EC activation and $\mathrm{HDL}$ can attenuate $\mathrm{PBMC}$ adherence by reducing ICAM-1 levels in aortic derived ECs [34], we also evaluated the roles of ICAM-1 and VCAM-1 in hCMEC/D3 activation. Using Western blotting, we observed that pretreatment of monotypic hCMEC/D3 cultures with HDL significantly suppressed TNF- $\alpha$-mediated induction of ICAM-1 (from $1343 \%$ to $920 \%, p=0.041$ ) and VCAM-1 (from $2838 \%$ to $1928 \% p=0.012$ ), relative to untreated cells (Additional file $6 \mathrm{a}-\mathrm{c})$, results that are consistent with HDL's antiinflammatory effects on peripherally derived ECs. By contrast, $A \beta$ treatment did not affect either mRNA levels or total protein levels of VCAM-1 and ICAM-1 in hCMEC/D3 (Additional file 6d-m). Although total ICAM-1 levels showed no significant change in response to either $A \beta 40$ or A $\beta 42$ treatment, biotinylation assays revealed significantly increased cell surface ICAM-1 levels, but not VCAM-1 levels, in response to $0.1 \mu \mathrm{M}$ of $\mathrm{A} \beta 40(p=0.009)$ and a strong trend in response to $\mathrm{A} \beta 42(p=0.06)$ (Additional file $6 \mathrm{~h}-\mathrm{j})$. Unexpectedly, however, we observed that cell surface ICAM- 1 levels were not reduced by a $2 \mathrm{~h}$ exposure to HDL (Additional file $6 \mathrm{k}-\mathrm{m}$ ), showing that cell surface ICAM-1 levels do not correlate with PMBC adhesion in $\mathrm{A} \beta$-activated hCMEC/D3. We next analysed the effects of $A \beta$ on the phosphorylation of multifunctional serine/threonine protein kinases that are involved in EC activation, survival, apoptosis, proliferation and migration. TNF- $\alpha$ activated NFKB p-P65 $(p=0.002)$, SAPK/JNK $(p=0.005)$, MAPK/ ERK $(p=0.01)$, but not Akt or STAT2 pathways, whereas $\mathrm{A} \beta$ did not alter any of these pathways in hCMEC/D3 (Additional file 7). Taken together, these results suggest that $A \beta$ does not activate any of classical inflammatory pathways known to increase PBMC adhesion through ICAM-1 or VCAM-1.

\section{Suppressing a $\beta$ uptake into hCMEC/D3 blocks PBMC adherence}

As our results show that $A \beta$ activates hCMEC/D3 through a mechanism that is independent of canonical EC activation intracellular signalling pathways, we hypothesised that binding or uptake of $A \beta$ to ECs might influence PBMC adhesion. To test this hypothesis, we first used temperature modulation experiments to investigate how HDL affects the interactions of $A \beta$ with hCMEC/D3 and observed that HDL pre-treatment significantly reduced total association measured at $37{ }^{\circ} \mathrm{C}$ (Fig. 5a,b), cell surface binding measured at $4{ }^{\circ} \mathrm{C}$ measured by ELISA (Fig. 5c,d) and intracellular uptake of fluorescently labeled $A \beta 40$ and $A \beta 42$ (Fig. 5e). Second, we tested whether blocking RAGE and LRP1, known receptors that modulate $\mathrm{A} \beta$ binding and uptake in ECs [35], might reduce PBMC adhesion. Blocking RAGE with a specific antibody abrogated PBMC adhesion to both $A \beta 40$ and $A \beta 42$ but not TNF- $\alpha$ stimulated hCMEC/D3(Fig. 5f-h). Similarly, blocking LRP1 with receptor associated protein (RAP) abolished $A \beta 40$ and A $\beta 42$ but not TNF- $\alpha$ effects (Fig. 5i-k). Finally, as heparin sulphate proteoglycans (HSPG) are also involved in binding and uptake of $A \beta$ in neuron [36], we then saturated or removed HSPG by treating hCMEC/D3 with heparin or heparinase III, respectively. Both treatments abolished the ability of $A \beta 40$ and $A \beta 42$ to induce PBMC binding whereas TNF- $\alpha$ induced-PBMC adhesion remained significant (Fig. 5l-n). Together, these observations show that, unlike TNF- $\alpha, A \beta$ induces PBMC adhesion to ECs through a pathway that requires interactions with or internalization through $\mathrm{A} \beta$ receptors on the $\mathrm{EC}$ surface. We also observed that HDL does not decrease the expression of RAGE or LRP1 (Additional file 8), suggesting that down-regulation of these receptors cannot explain the protective effect of $\mathrm{HDL}$ on $\mathrm{A} \beta$-induced PBMC binding to hCMEC/D3.

\section{Scavenger receptor-BI (SR-BI) is necessary for HDL to sup- press a $\beta$-induced PBMC adhesion to ECs}

Scavenger receptor BI (SR-BI) is the principal HDL receptor on ECs and activates several HDL signalling pathways in addition to mediating selective cholesterol uptake upon HDL docking [37]. We observed that inhibiting SR-BI binding with a specific blocking antibody abolished the ability of HDL to suppress both A $\beta$ - and TNF- $\alpha$-mediated PBMC adhesion to hCMEC/D3 (Fig. 6a-c). Selectivity to SR-BI was confirmed by demonstrating that blocking scavenger receptor CD36 with a specific antibody had no effect on the ability of HDL to suppress either $\mathrm{A} \beta$ or TNF- $\alpha$-mediated PBMC adhesion to hCMEC/D3 (Fig. 6d-f). Intriguingly, inhibiting SR-BI-mediated selective cholesterol uptake with block lipid transfer 1 (BLT1) did not affect the ability of HDL to suppress either $A \beta$ - or TNF- $\alpha$-mediated PBMC adhesion to hCMEC/D3 (Fig. 6g-i). We further observed that inhibiting SR-BI with a specific blocking antibody abolished the ability of HDL to suppress A $\beta$ uptake in hCMEC/D3 (Fig. 6j). These results demonstrate that $\mathrm{HDL}$ requires $\mathrm{SR}-\mathrm{BI}$-mediated signalling to inhibit $A \beta$ uptake and subsequently suppress PBMC adhesion to hCMEC/D3 in response to $A \beta$ - or TNF- $\alpha$ in a manner independent of lipid uptake.

Having used monotypic static cell cultures to demonstrate that HDL suppresses $A \beta$-induced PBMC adhesion to endothelial cells through a mechanism that requires SR-BI and is independent of ICAM-1 expression, we confirmed that this mechanism also explains the results in our 3D bioengineered vessels. We observed that inhibiting SR-BI 

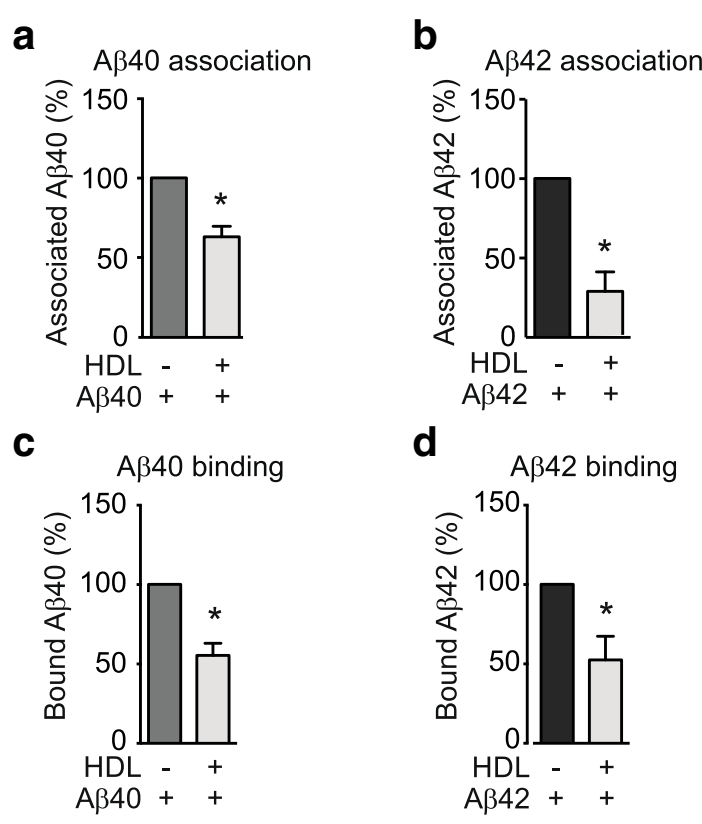

d
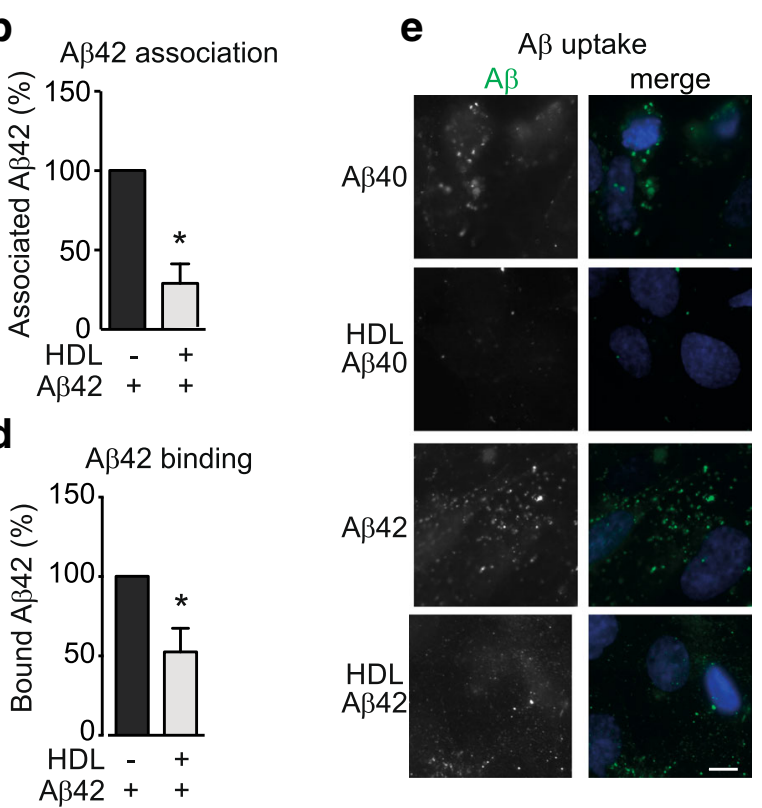

f

PBMC adhesion

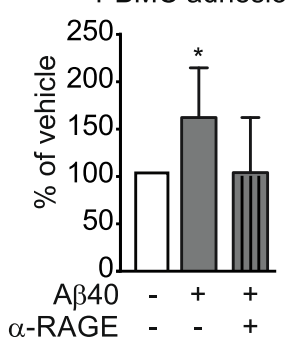

g
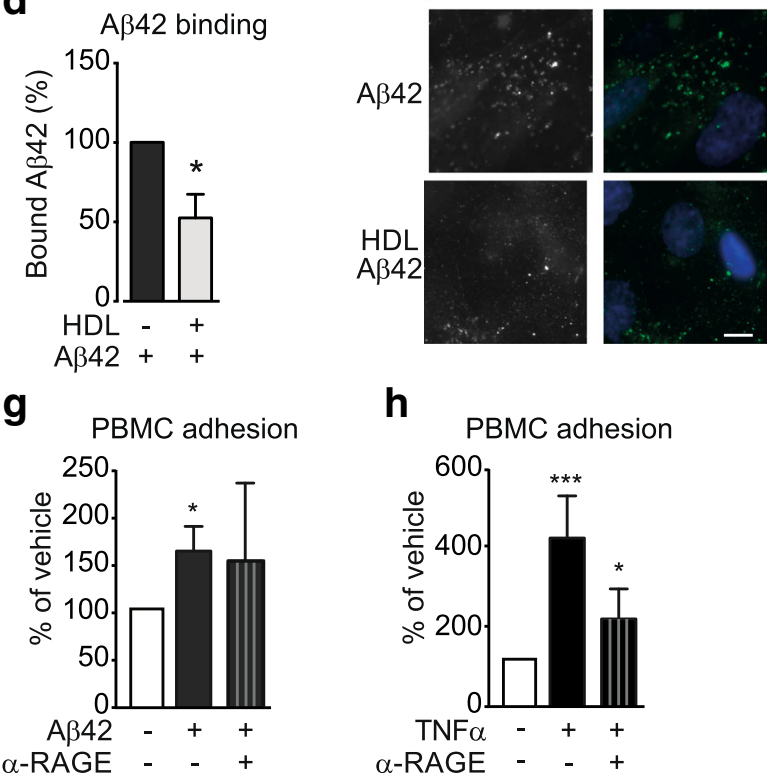

HDL

A 342

h

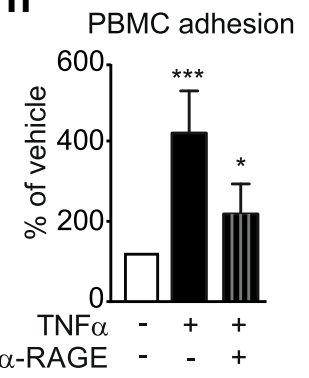

i

j PBMC adhesion
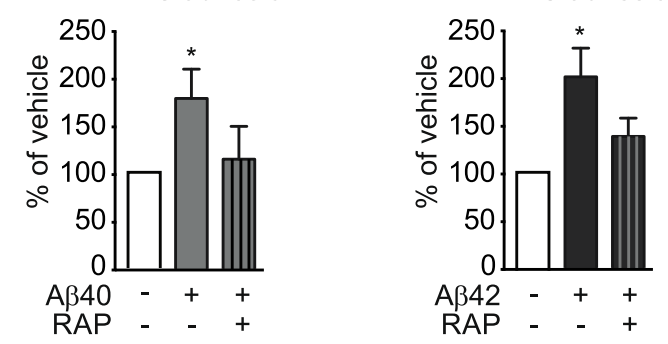

k PBMC adhesion

PBMC adhesion

m

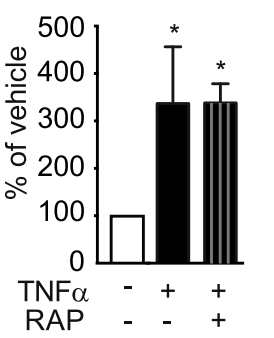

n
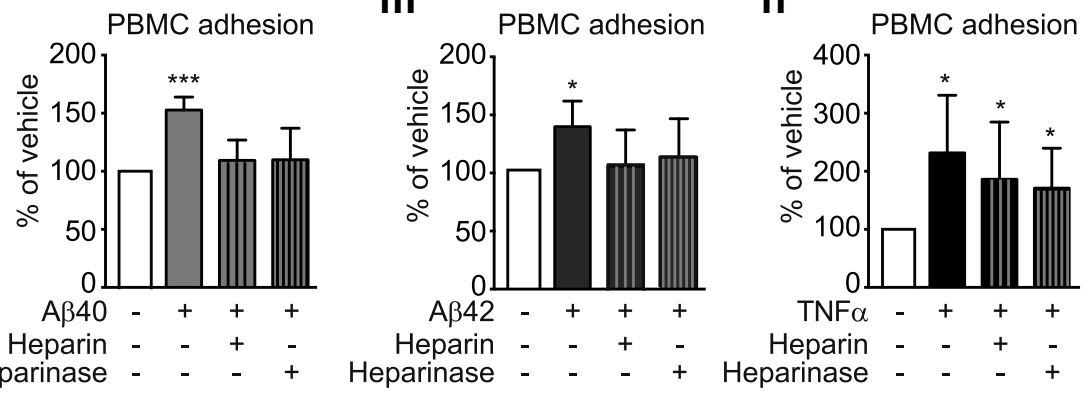

Fig. 5 (See legend on next page.) 
(See figure on previous page.)

Fig. $5 \mathrm{HDL}$ reduces $A \beta$ association, binding and uptake to hCMEC/D3 whereas blocking A $\beta$ binding or uptake reduces PBMC adhesion to hCMEC/D3. a-d hCMEC/D3 were pre-treated with $100 \mu \mathrm{g} / \mathrm{mL}$ of HDL and $0.1 \mu \mathrm{M} \mathbf{a}, \mathbf{c} A \beta 40$ or $\mathbf{b}, \mathbf{d} A \beta 42$ monomers as described in Fig. 2 at either $37^{\circ} \mathrm{C}$ (association $\mathbf{a}, \mathbf{b}$ ) or at $4^{\circ} \mathrm{C}$ (binding $\mathbf{c}, \mathbf{d}$ ). Cells were lysed in RIPA buffer and A $\beta$ were measured using commercial ELISA. e hCMEC/D3 were pre-treated with $\mathrm{HDL}(1 \mathrm{mg} / \mathrm{mL})$ for $2 \mathrm{~h}$ before stimulating with $1 \mathrm{mM}$ of fluorescently labelled Aß40 or Aß42 monomers. Scale bar represents $10 \mu \mathrm{m}$. f-n hCMEC/D3 were pre-treated with (f-h) RAGE blocking antibody, i-k RAP or I-n heparin or heparinase III 60 min before stimulation with $A \beta 40$ or A $\beta 42$ monomers or TNF- $a$ for 3 h. PBMC adhesion assays were conducted as described in Fig. 2. Graphs represent means \pm SD relative to vehicle treated cells for at least 3 independent trials. ${ }^{*} p<0.05$, ${ }^{* *} p<0.01$ versus vehicle

with a specific antibody circulated through the vessel lumen abolished the ability of HDL to suppress $A \beta$-mediated monocyte adhesion to the vascular endothelium (Fig. 7a-b) without reducing ICAM-1 expression (Fig. 7c-d).

\section{Discussion}

Far from being an inert vascular lining, ECs form a metabolically active and specialized interface between blood and underlying tissues. In response to an inflammatory stimulus, ECs undergo activation, which is classically defined by increased interaction with blood leukocytes. EC dysfunction plays a central role in peripheral vascular disease, stroke, heart disease, diabetes, insulin resistance, chronic kidney failure, tumor growth, metastasis, venous thrombosis, and severe viral infectious diseases [38]. The richly vascularized human brain contains ECs that form the nearly impenetrable BBB, which regulates the flux of substances in and out of the CNS. The contribution of cerebrovascular dysfunction in dementia and cognitive decline is well acknowledged $[39,40]$, yet pathways that mediate cerebrovascular EC dysfunction and protection are not well understood.

Using classical PMBC adhesion assays, we demonstrate that $A \beta$ can act as an inflammatory stimulus to increase PBMC adhesion to brain microvascular ECs that can be suppressed by HDL. Our results show that the ability of HDL to attenuate $A \beta$-induced PBMC adhesion to ECs is independent of $A \beta$ structure, NO production, miR-223 and, unexpectedly, of ICAM-1 and VCAM-1 expression. Rather, HDL requires SR-BI to suppress A $\beta$ mediated PBMC adhesion to ECs, which can also be attenuated by inhibiting internalization of $A \beta$ by blocking RAGE or LRP1, or by inhibiting A $\beta$-HSPG interactions. We also show that HDL can also prevent $A \beta$ fibrillization, suggesting that HDL may also help to maintain $A \beta$ solubility as it transits across the $B B B$. However, as this function of HDL is relatively slow, it is unlikely to account for HDL's ability to suppress $A \beta$ mediated PBMC adhesion to ECs. Our observations are consistent with a previous study that demonstrated that deficiency of SR-BI increases cerebrovascular amyloid deposition in the J20 mouse model of AD [41].

As ICAM-1 levels are clearly elevated in AD cortex, and previous studies have reported induced adhesion molecule expression after $A \beta$ stimulation [42], we were surprised to observe that $A \beta$ had negligible effects on adhesion molecule expression and kinase activation under our experimental conditions, whereas TNF- $\alpha$ robustly induces ICAM-1 and VCAM-1 expression as well as NFKB, MAPK/ERK, and SAPK/JNK signalling. The cellular processes triggered by internalized $A \beta$ that promote PBMC adhesion remain to be determined.

In cultured aortic ECs, HDL reduces adhesion molecule expression and subsequent monocyte binding via a mechanism involving SR-BI signalling through eNOS, which requires the S1P receptor [25]. Our observations that HDL's ability to suppress A $\beta$ - and TNF- $\alpha$-mediated $\mathrm{PBMC}$ adhesion to hCMEC/D3 is independent of NO production and S1P activity suggests that brain ECs may have pathways distinct from ECs derived from arterial sources, at least under the culture conditions used here. Reduced eNOS expression in the AD brain has been hypothesized to increase $A \beta$ deposition and promote production of reactive oxygen species production, which reduces vasomotor regulation of penetrating arterioles $[43,44]$. HDL clearly induces NO production in hCMEC/D3 and HUVEC, and although NO production is not required to protect $\mathrm{hCMEC/D} 3$ from $\mathrm{A} \beta$ - or TNF- $\alpha$ mediated PBMC adhesion per se, HDLstimulated NO production may provide beneficial effects on other cerebrovascular EC functions.

A wealth of studies have explored in vitro associations of $\mathrm{A} \beta$ with lipoprotein components, primarily focussing on apoE as genetic variants of apoE have established effects on $A \beta$ metabolism in $A D$ [45]. As $A \beta$ is a hydrophobic peptide, it is not surprising that it associates with lipoprotein particles, and also to amphipathic apolipoproteins. Elucidating the structure-function relationships of $A \beta$ with lipoproteins remains an active area of research. While $A \beta$ might associate with plasma lipoproteins [46], the effect of HDL on $A \beta$ structure remains poorly understood. Interestingly, HDL constituents on their own have been reported to both interact with $A \beta$ and diminish its toxic effects. Specifically, small liposomes $(<50 \mu \mathrm{m})$ accelerate $A \beta 40$ fibrillization and the amounts of amorphous aggregates become larger as liposome increase $(>50 \mu \mathrm{m})$ [47]. By contrast, nanoliposomes $(100 \mathrm{~nm})$ prevent $\mathrm{A} \beta 42$ fibrillization and reduces A $\beta 42$-induced EC dysfunctions [48]. In addition, lipidfree apoA-I induces $A \beta$ aggregation and generation of 


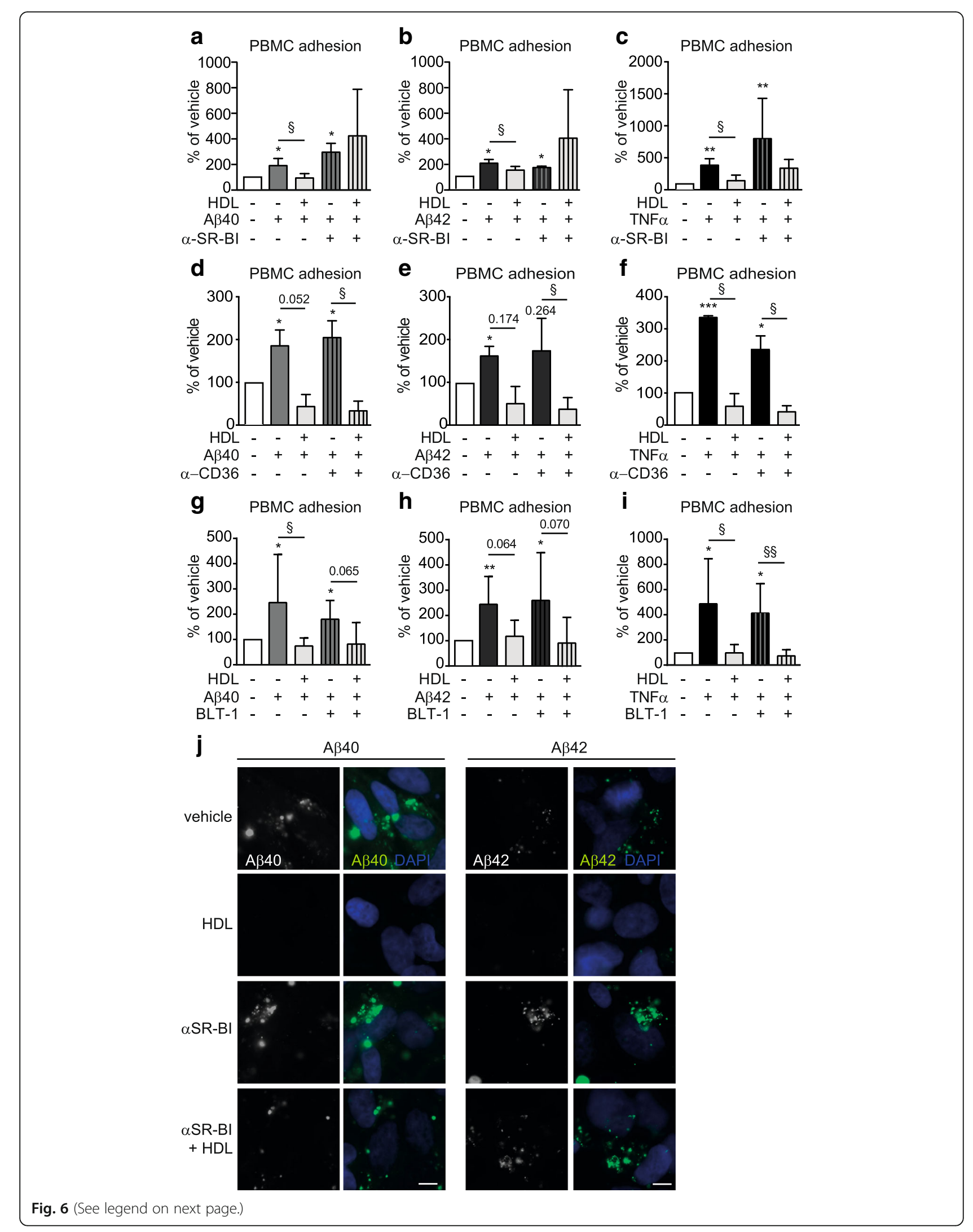


(See figure on previous page.)

Fig. $6 \mathrm{HDL}$ suppression of $A \beta$-induced inflammation requires SR-BI. hCMEC/D3 were pre-treated for $1 \mathrm{~h}$ with a-c SR-BI or d-f CD36 blocking antibodies or $\mathbf{g}-\mathbf{i}$ BLT1 followed by $100 \mu \mathrm{g} / \mathrm{mL}$ HDL for $2 \mathrm{~h}$. Cells were then stimulated with $0.1 \mu \mathrm{M}$ monomeric $\mathbf{a}, \mathbf{d}, \mathbf{g}$ A 340 or $\mathbf{b}, \mathbf{e}, \mathbf{h}$ A 342 or $(\mathbf{c}, \mathbf{f}, \mathbf{i}) 1 \mathrm{ng} / \mathrm{mL}$ of TNF-a for $3 \mathrm{~h}$ before evaluating PBMC adherence. $\mathbf{j}$ hCMEC/D3 were pre-treated for $1 \mathrm{~h}$ with SR-Bl blocking antibody followed by HDL $(1 \mathrm{mg} / \mathrm{mL})$ for $2 \mathrm{~h}$ before stimulating with $1 \mathrm{mM}$ of fluorescently labelled A 340 or A 342 monomers. Scale bar represents $10 \mu \mathrm{m}$. Graphs represent means \pm SD of adhered PBMC relative to vehicle treated cells from at least 4 independent trials. ${ }^{*} p<0.05,{ }^{* *} p<0.01,{ }^{* * *} p<0.001{ }^{*}$ $p<0.05,{ }^{* *} p<0.01,{ }^{* * *} p<0.001$ versus vehicle, $\S p<0.05$ versus $A \beta$ or TNF-a.

amorphous complexes, both of which reducing amyloid toxicity [22]. Our results clearly show that mature HDL delays $A \beta$ fibrillization in a cell-independent assay with substantially slower kinetics than HDL's ability to attenuate $\mathrm{A} \beta$-induced PBMC adhesion to ECs. As HDL also reduces $A \beta$-induced PBMC adhesion to ECs independent of monomeric vs. oligomeric input structures, we believe that HDL's ability to delay $A \beta$ fibrillization is a distinct function compared to reduce $A \beta$-inflammation, which relies exclusively to a cellular process involving SR-BI.

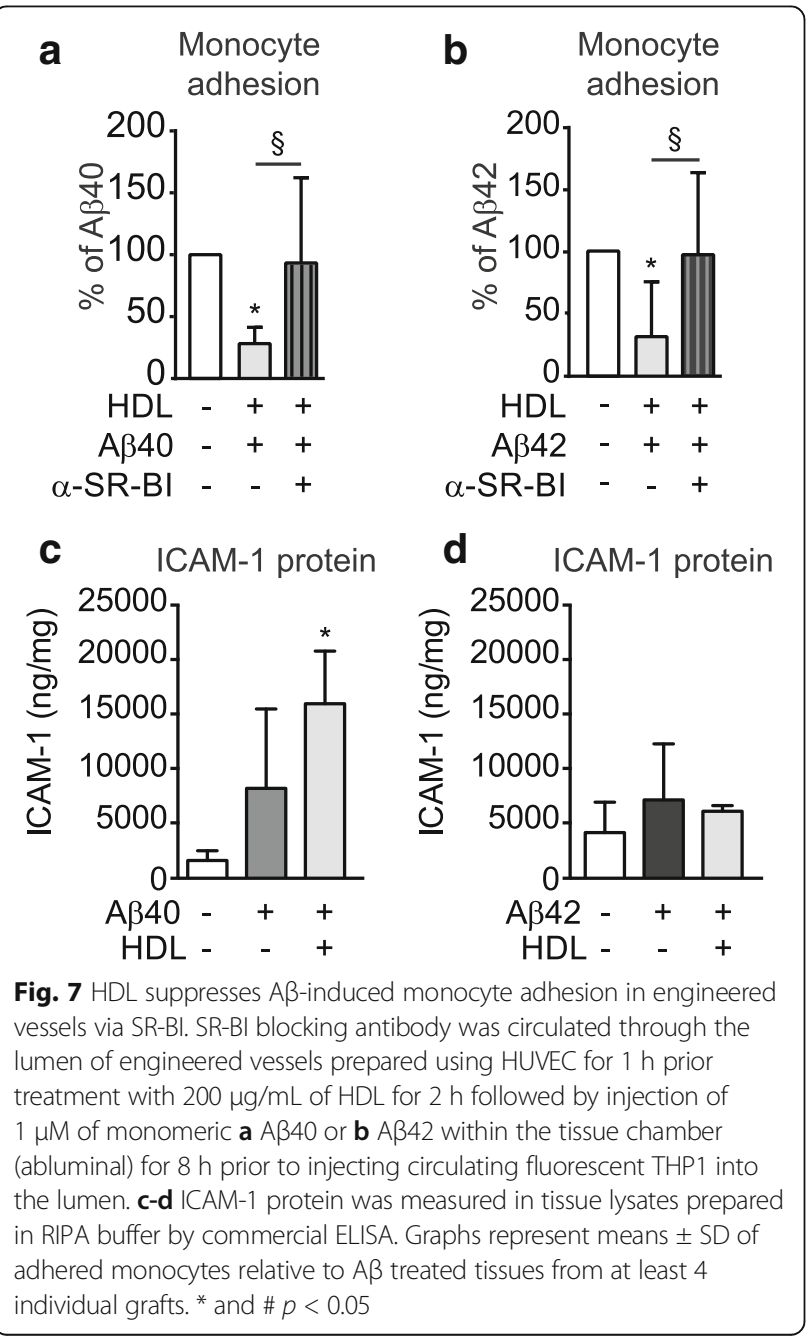

As traditional static monotypic cell cultures do not reproduce the physiological complexity of the native vascular bed, we also used a 3D model of the human vasculature in our studies. These engineered vessels mimic a native vessel with a luminal monolayer of human ECs surrounded by several layers of human SMCs, through which human mononuclear cells can be circulated under flow conditions. This model has been previously used to study atherosclerosis in peripheral arteries [17]. Here, we injected $A \beta$ on the anteluminal side to mimic brainproduced $A \beta$ and circulated HDL and monocytes through the lumen. We confirmed that $A \beta$ induces monocyte adhesion to ECs under native-like flow conditions in engineered human vessels, which can be suppressed by HDL through a mechanism that requires SR-BI and that is independent of changes in ICAM-1 levels.

\section{Conclusion}

Numerous studies show that HDL has several properties that are associated with improved vascular function [49]. While some lines of evidence also suggest a beneficial role for HDL in protecting from cognitive decline, the nature of this association remains largely unknown. Whereas lipid-free apoA-I can be transported into the CNS [50], there is thus far no evidence that mature HDL might cross the $\mathrm{BBB}$, supporting the view that HDL might act predominately from the blood compartment and would therefore primarily affect ECs. Our data suggest at least three mechanisms by which HDL could have beneficial effects on cerebral vessels. First, HDL prevents $A \beta$-induced PBMC adhesion to brain microvascular ECs through a mechanism that requires SR-BI and suppresses $A \beta$ uptake. The cellular pathways by which internalized $\mathrm{A} \beta$ promotes $\mathrm{PBMC}$ adhesion to ECs remains to be defined, and appears to be distinct from those induced by classical inflammatory stimuli. Second, similar to its effects in peripheral EC, HDL induces NO secretion in hCMEC/D3. Although we ruled out a role for eNOS in $\mathrm{A} \beta$-induced PBMC adhesion, HDLstimulated NO production may still help to attenuate vasomotor dysfunction as observed in the aging brain [44]. Third, although HDL can protect hCMEC/D3 from PBMC adhesion independent of $A \beta$ structure, the ability of HDL to maintain $A \beta$ in a soluble state may facilitate efficient $A \beta$ clearance out of the brain. 


\section{Additional files}

Additional file 1: $A \beta$ induced dose dependent PBMC adhesion and $\mathrm{HDL}$ attenuate dose dependent A $\beta$-induced PBMC adhesion to hCMEC/D3. In all conditions, hCMEC/D3 were stimulated with 0-1 $\mu \mathrm{M}$ AB40 (light grey) or A 42 (dark grey) monomers for $3 \mathrm{~h}$. Fluorescently labelled PBMC were allowed to adhere to (a) A 340 - or (b) Aß42- stimulated cells for 3 additional hours. Cells were washed, fixed, and imaged to count adhered PBMC. hCMEC/D3 were primed with increasing doses $(25-400 \mu \mathrm{g} / \mathrm{mL})$ of HDL for $2 \mathrm{~h}$ and stimulated with $0.1 \mu \mathrm{M}$ (c) A 440 (light grey) or (d) A 442 (dark grey) for $3 \mathrm{~h}$. Fluorescently labelled PBMC were allowed to adhere to stimulated cells for $3 \mathrm{~h}$ followed by washing, fixation, imaging, and counting. Graphs represent mean \pm SD of adhered $\mathrm{PBMC}$ relative to vehicle control from at least 3 independent trials where ${ }^{*} p<0.05,{ }^{* *} p<0.01,{ }^{* * *} p<0.001$ versus vehicle, $\S p<0.05, \S \S p<0.01$ versus $A \beta$ (PDF $422 \mathrm{~kb}$ )

Additional file $\mathbf{2} \mathrm{HDL}$ suppression of $A \beta$-induced inflammation is independent of eNOS and S1P in HUVEC. (a) L-NAME and (e) VPC23019 potency was tested by measuring intracellular NO production in HUVEC after incubating with $100 \mu \mathrm{g} / \mathrm{mL} \mathrm{HDL}$ and $1 \mu \mathrm{M}$ DAF-2 for $6 \mathrm{~h}$. Fluorescence was measured at $485 \mathrm{~nm}$. (b-d, $\mathbf{f - h}$ ) In all conditions, HUVEC or hCMEC/D3 were stimulated with $0.1 \mu \mathrm{M}$ monomeric $A \beta 40$ or $A \beta 42$ or $1 \mathrm{ng} / \mathrm{mL}$ of TNF-a for $3 \mathrm{~h}$ prior to measuring PBMC adherence. HUVEC were pre-treated for $1 \mathrm{~h}$ with $(\mathbf{b}-\mathbf{d})$ the eNOS inhibitor L-NAME or $(\mathbf{f}-\mathbf{h})$ the S1P1 and S1P3 inhibitor VPC23019 followed by $100 \mu \mathrm{g} / \mathrm{mL}$ HDL for $2 \mathrm{~h}$. (i) hCMEC/D3 were pre-treated with $100 \mu \mathrm{g} / \mathrm{mL}$ of HDL for $2 \mathrm{~h}$ before simulating with $\mathrm{A} \beta 40$ or A 4 42. Total cellular expression of Annexin-1 (Anx1) was analysed by immunoblotting and compared to GAPDH. Graphs represent means \pm SD from at least 3 independent trials. ${ }^{*} p<0.05,{ }^{* *} p<0.01$, ${ }^{* * *} p<0.001$, ${ }^{* * * *} p<0.0001$ versus vehicle, $\S p<0.05, \S \S p<0.01, \S \S \S p<0.001, \S \S \S \S$ $p<0.0001$ versus $A \beta$ or TNF-a (PDF $1059 \mathrm{~kb})$

Additional file 3: $H D L$ does not signal through miR-223 to reduce $A \beta$ induced inflammation in hCMEC/D3. (a-c) hCMEC/D3 were pre-treated with $100 \mu \mathrm{g} / \mathrm{mL}$ of $\mathrm{HDL}$ as described in Fig. 2 with or without $10 \mathrm{nM}$ of miR-223 mimetic nucleotides or (d-f) in the absence or presence of a specific miR223

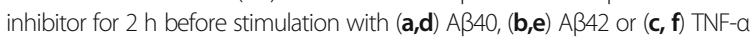
before testing PBMC adherence to ECs. (g) Intracellular levels of mature miR-223 in hCMEC/D3 were quantified by real-time PCR and normalized to U6 after a 5 h treatment with $100 \mu \mathrm{g} / \mathrm{mL}$ of HDL. Graphs represent means \pm SD of adhered PBMC relative to vehicle treated cells for at least 5 independent trials. ${ }^{*} p<0.05,{ }^{* *} p<0.01,{ }^{* * *} p<0.001{ }^{*} p<0.05,{ }^{* *} p<0.01,{ }^{* * *} p<0.001$ versus vehicle, $\S p<0.05, \S \S p<0.01, \S \S \S p<0.001$ versus $A \beta$ or TNF-a (PDF $464 \mathrm{~kb})$

Additional file 4: Demographic data, $A \beta 40$ and $A \beta 42$, and adhesion molecule quantification in Alzheimer's disease patients and non-cognitive impaired controls (PDF $431 \mathrm{~kb}$ )

Additional file 5: Cortical ICAM-1 expression is increased in AD. Cryopreserved cortex and cerebellum of AD or NCl patients were cut at $20 \mu \mathrm{m}$. After PFA fixation sections were washed with PBS and stained against (a) ICAM-I or (b) VCAM-1 and CD31 as a vascular marker and imaged using an inverted fluorescent microscope. Arrow demonstrates colocalization of ICAM-1 and CD31. Bar represents 50 นm (PDF 62676 kb)

Additional file 6: Adhesion molecules are enhanced by TNF-a but not A 3. (a-c) hCMEC/D3 were primed with $100 \mu \mathrm{g} / \mathrm{mL} \mathrm{HDL}$ for $2 \mathrm{~h}$ followed by stimulation with $1 \mathrm{ng} / \mathrm{mL}$ TNF-a for $3 \mathrm{~h}$. Cell lysates were prepared in RIPA and protein levels of (a) ICAM-1 and (b) VCAM-1 were measured by denaturing immunoblotting (c). (d-g) hCMEC/D3 were stimulated with monomeric $(\mathbf{d}, \mathbf{f}) A \beta 40$ or $(\mathbf{e}, \mathrm{g}) \mathrm{A} \beta 42$ at the indicated concentrations and $(\mathbf{d}, \mathbf{e})$ ICAM-1 and $(\mathbf{f}, \mathbf{g})$ VCAM-1 mRNA levels were measured by real-time PCR. (h-j) Following A $\beta$ stimulation, cell surface proteins were biotinylated and isolated by immunoprecipitation. Protein levels of cell surface and total (h) ICAM-1 and (i) VCAM-1 were measured by denaturing immunoblotting (j). (k-m) hCMEC/D3 were pre-treated with $100 \mu \mathrm{g} / \mathrm{mL}$ of $\mathrm{HDL}$ for $2 \mathrm{~h}$ followed by stimulation with $\mathrm{A} \beta$. After $3 \mathrm{~h}$ total and cell surface ICAM-1 expression were measured as above. Graphs represent means \pm SD from at least 3 independent trials. ${ }^{* *} p<0.001$ versus vehicle, $\S p<0.05$, versus $A \beta$ or TNF-a (PDF $2282 \mathrm{~kb}$ )

Additional file 7: $A \beta$ does not activate phosphorylation of multifunctional serine/threonine protein kinases. hCMEC/D3 were stimulated with $0.1 \mathrm{mM}$ of monomeric $A \beta$ or $1 \mathrm{ng} / \mathrm{mL}$ of TNF-afor 15 min before lysing cells in RIPA containing phosphostop. Phosphorylation of (a-b) p65, (c) STAT3, (d) Akt, (e) SAPKJNKK and (f) p42/44 MAPK were analysed by immunoblotting and compared to respective total p65, STAT3, Akt, SAPKJJNK and p42/44 MAPK respectively. (b) Nuclear translocation of p65 was analysed by immunofluorescence 15 min after $A \beta$ stimulation. Graphs represent means \pm SD relative to vehicle treated cells in 4 trials. ${ }^{*} p<0.05,{ }^{* *} p<0.01$ (PDF $9645 \mathrm{~kb}$ )

Additional file 8: HDL treatment does not alter LRP1 or RAGE protein levels in hCMEC/D3. (a-c) hCMEC/D3 were treated with HDL (0-400 $\mu \mathrm{g} /$ $\mathrm{mL}$ ) for $5 \mathrm{~h}$ before lysing in RIPA. (a) LRP1 and (b) RAGE protein levels were quantified by immunoblotting $(\mathbf{c})$. Graphs represent means \pm SD relative to vehicle treated cells in 3 trials (PDF $1114 \mathrm{~kb}$ )

\section{Abbreviations}

AD: Alzheimer Disease; Aß: Beta-amyloid peptide; BLT-1: Block lipid transport 1; CAA: Cerebral amyloid angiopathy; CNS: Central nervous system; EBM2: Endothelial growth basal medium; EC: Endothelial cell; eNOS: Endothelial nitric oxide synthase; FBS: Fetal bovine serum; FITC: Fluorescein isothiocyanate; hBMEC: Human brain microvascular endothelial cell; hCMEC/ D3: Human cortical microvascular endothelial cell line D3; HDL: High density lipoprotein; hSMC: Human smooth muscle cell; HSPG: Heparan sulphate proteoglycan; ICAM-1: Inducible cellular adhesion molecule-1; L-NAME: LNG-nitroarginne methyl ester; LRP1: Low density lipoprotein receptor related protein-1; NO: Nitric oxide; PBMC: Peripheral blood mononuclear cell; RAGE: Receptor of advanced glycation endproducts; SR-BI: Scavenger receptor BI; VCAM-1: Vascular cell adhesion molecule -1

\section{Acknowledgements}

Not applicable

\section{Funding}

This work was supported by operating grants from the Canadian Institutes of Health Research (CIHR), a Canadian Consortium of Neurodegeneration and Aging (CCNA), a Djavad Mowafaghian Centre for Brain Health Catalyst grant, philanthropic funding from the Jack Brown and Family Alzheimer's Research Foundation, the Y.P. Heung Foundation, and a private BC-based foundation to CLW, and a Weston Brain Institute Rapid Response grant to JR. JR was supported by a BrightFocus postdoctoral fellowship and a Swiss National Science Foundation Early.postdoctoral fellowship. EB was supported by a CIHR Doctoral Scholarship. GKB was supported by a UBC four years doctoral Fellowship. IK was supported in part by a Weston Brain Institute Rapid Response grant. NC was supported by CIHR and Brain Canada and GF was supported by a CIHR Project Grant 148,883 (GAF).

\section{Availability of supporting data:}

All data generated or analysed during this study are included in this published article and its supplementary information files.

\section{Author contributions}

$J R, E B$ and CLW conceived the project. JR and EB made equivalent contributions to this study and performed most of the experiments with assistance from SS, GKB, EG, CC, WHC, SKS, BY, MG, AB, KK and IK. Data analysis was primarily performed by JR. EB, and CLW, who together wrote the manuscript with assistance from EG, GF and NC. The authors declare no competing financial interests. All authors read and approved the final manuscript.

\section{Authors' information}

Not applicable

\section{Ethical approval and consent to participate}

All experiments were conducted under an approved clinical protocol from the UBC Clinical Ethics Research Board after obtaining written informed consent from all subjects (H13-02719: isolation of vascular cells and H14-03357: isolation of lipoprotein and PBMC).

\section{Consent for publication}

Not applicable 


\section{Competing interests:}

The authors declare that they have no competing interests.

\section{Publisher's Note}

Springer Nature remains neutral with regard to jurisdictional claims in published maps and institutional affiliations.

\section{Author details}

'Department of Pathology and Laboratory Medicine, University of British Columbia, Vancouver, BC V6T 1Z3, Canada. ${ }^{2}$ Djavad Mowafaghian Centre for Brain Health, University of British Columbia, 2215 Wesbrook Mall, Vancouver, BC V6T 1Z3, Canada. ${ }^{3}$ Department of Neurology, University of British Columbia, Vancouver, BC V6T 2B5, Canada. ${ }^{4}$ Department of Zoology, University of British Columbia, Vancouver, BC V6T 2B5, Canada. ${ }^{5}$ Department of Medicine, University of British Columbia, Vancouver, BC V6Z 1Y6, Canada.

\section{Received: 4 May 2017 Accepted: 7 August 2017}

\section{Published online: 22 August 2017}

\section{References}

1. Alzheimer's Association. 2015 Alzheimer's disease facts and figures. Alzheimer's \& dementia : the journal of the Alzheimer's Association. 2015;11(3):332-84

2. Perl DP. Neuropathology of Alzheimer's disease. The Mount Sinai journal of medicine, New York [Internet]. 2010;77(1):32-42.

3. Debette S. Vascular risk factors and cognitive disorders. Rev Neurol. 2013; 169(10):757-64.

4. Justin BN, Turek M, Hakim AM. Heart disease as a risk factor for dementia. Clin Epidemiol. 2013;5:135-45.

5. Craft S. The role of metabolic disorders in Alzheimer disease and vascular dementia: two roads converged. Arch Neurol. 2009;66(3):300-5.

6. Schneider JA, Arvanitakis Z, Bang W, Bennett DA. Mixed brain pathologies account for most dementia cases in community-dwelling older persons. Neurology. 2007;69(24):2197-204

7. Tarasoff-Conway JM, Carare RO, Osorio RS, Glodzik L, Butler T, Fieremans E, Axel L, Rusinek H, Nicholson C, Zlokovic BV, Frangione B, Blennow K, Ménard J, Zetterberg H. Wisniewski T, de Leon MJ. Clearance systems in the brain-implications for Alzheimer disease. Nat Rev Neurol. 2015;11(8):457-70.

8. Grammas P. Neurovascular dysfunction, inflammation and endothelial activation: implications for the pathogenesis of Alzheimer's disease. J Neuroinflammation. 2011:8:26.

9. Kontush A, Lhomme M, Chapman MJ. Unraveling the complexities of the HDL lipidome. J Lipid Res. 2013;54(11):2950-63.

10. Shah AS, Tan L, Lu Long J, Davidson WS. The proteomic diversity of high density lipoproteins: our emerging understanding of its importance in lipid transport and beyond. J Lipid Res. 2013 Feb;24

11. Mahdy Ali K, Wonnerth A, Huber K, Wojta J. Cardiovascular disease risk reduction by raising $\mathrm{HDL}$ cholesterol-current therapies and future opportunities. Br J Pharmacol. 2012;167(6):1177-94.

12. Zuliani G, Cavalieri M, Galvani M, Volpato S, Cherubini A, Bandinelli S, Corsi AM, Lauretani F, Guralnik JM, Fellin R, Ferrucci L. Relationship between low levels of high-density lipoprotein cholesterol and dementia in the elderly. The InChianti study. J Gerontol A Biol Sci Med Sci. 2010;65(5):559-64.

13. Lefterov I, Fitz NF, A CA, Fogg A, Lefterov P, Kodali R, Wetzel R, Koldamova R. Apolipoprotein A-I deficiency increases cerebral amyloid angiopathy and cognitive deficits in APP/PS1DeltaE9 mice. J Biol Chem. 2010;285(47):36945-57.

14. Lewis TL, Cao D, Lu H, Mans RA, Su YR, Jungbauer L, Linton MF, Fazio S, Mj LD, Li L. Overexpression of human apolipoprotein A-I preserves cognitive function and attenuates neuroinflammation and cerebral amyloid angiopathy in a mouse model of Alzheimer disease. J Biol Chem. 2010; 285(47):36958-68.

15. Robert J, Stukas S, Button E, Cheng WH, Lee M, Fan J, Wilkinson A, Kulic I, Wright SD, Wellington CL. Reconstituted high-density lipoproteins acutely reduce soluble brain A levels in symptomatic APP/PS1 mice. Biochim Biophys Acta. 2015;1862(5):1027-36.

16. Riwanto $M$, Landmesser U. High-density lipoproteins and endothelial functions: mechanistic insights and alterations in cardiovascular disease. J Lipid Res. 2013:54(12):3227-43.

17. Robert J, Weber B, Frese L, Emmert MY, Schmidt D, von Eckardstein A, Rohrer L, Hoerstrup SP. A three-dimensional engineered artery model for in vitro atherosclerosis research. PLoS One. 2013;8(11):e79821.
18. Hoerstrup SP, Cummings Mrcs I, Lachat M, Schoen FJ, Jenni R, Leschka S, Neuenschwander S, Schmidt D, Mol A, Günter C, Gössi M, Genoni M, Zund G. Functional growth in tissue-engineered living, vascular grafts: follow-up at 100 weeks in a large animal model. Circulation. 2006;114:1159-66.

19. Robert J, Lehner M, Frank S, Perisa D, von Eckardstein A, Rohrer L. Interleukin 6 stimulates endothelial binding and transport of high-density lipoprotein through induction of endothelial lipase. Arterioscler Thromb Vasc Biol. 2013;33(12):2699-706

20. Czupalla CJ, Liebner S, Devraj K. In vitro models of the blood-brain barrier. Methods in molecular biology (Clifton, NJ). 2014;1135:415-37.

21. Koudinov AR, Berezov TT, Koudinova NV. The levels of soluble amyloid beta in different high density lipoprotein subfractions distinguish Alzheimer's and normal aging cerebrospinal fluid: implication for brain cholesterol pathology. Neurosci Lett. 2001;314(3):115-8.

22. Paula-Lima AC, Tricerri MA, Brito-Moreira J, Bomfim TR, Oliveira FF, Magdesian MH, Grinberg LT, Panizzutti R, Ferreira ST. Human apolipoprotein A-I binds amyloid-beta and prevents Abeta-induced neurotoxicity. Int J Biochem Cell Biol. 2009;41(6):1361-70.

23. Lee SJC, Nam E, Lee HJ, Savelieff MG, Lim MH. Towards an understanding of amyloid- $\beta$ oligomers: characterization, toxicity mechanisms, and inhibitors. Chem Soc Rev. 2016:46(2):310-23.

24. Stine WB, Jungbauer $L, Y u C$, LaDu MJ. Preparing synthetic $A \beta$ in different aggregation states. Methods in molecular biology (Clifton, NJ). 2011;670:13-32.

25. Besler C, Heinrich K, Rohrer L, Doerries C, Riwanto M, Shih DM, Chroni A, Yonekawa K, Stein S, Schaefer N, Mueller M, Akhmedov A, Daniil G, Manes C, Templin C, Wyss C, Maier W, Tanner FC, Matter CM, Corti R, Furlong C, Lusis AJ von Eckardstein A, Fogelman AM, Luscher TF, Landmesser U. Mechanisms underlying adverse effects of HDL on eNOS-activating pathways in patients with coronary artery disease. J Clin Invest. 2011;121(7):2693-708,

26. Tölle M, Klöckl L, Wiedon A, Zidek W, van der Giet M, Schuchardt M. Regulation of endothelial nitric oxide synthase activation in endothelial cells by S1P1 and S1P3. Biochem Biophys Res Commun. 2016:476(4):627-34.

27. Pan B, Kong J, Jin J, Kong J, He Y, Dong S, Ji L, Liu D, He D, Kong L, Jin DK, Willard B, Pennathur S, Zheng L. A novel anti-inflammatory mechanism of high density lipoprotein through up-regulating annexin $A 1$ in vascular endothelial cells. Biochim Biophys Acta. 2016;1861(6):501-12.

28. Vickers KC, Palmisano BT, Shoucri BM, Shamburek RD, Remaley AT. MicroRNAs are transported in plasma and delivered to recipient cells by high-density lipoproteins. Nat Cell Biol. 2011;13(4):423-33.

29. Tabet F, Vickers KC, Cuesta Torres LF, Wiese CB, Shoucri BM, Lambert G, Catherinet C, Prado-Lourenco L, Levin MG, Thacker S, Sethupathy P, Barter PJ, Remaley AT, Rye K-A. HDL-transferred microRNA-223 regulates ICAM-1 expression in endothelial cells. Nat Commun. 2014;5:3292.

30. Wagner J, Riwanto M, Besler C, Knau A, Fichtlscherer S, Röxe T, Zeiher AM, Landmesser U, Dimmeler S. Characterization of levels and cellular transfer of circulating lipoprotein-bound microRNAs. Arterioscler Thromb Vasc Biol. 2013:33(6):1392-400.

31. Lawson C, Wolf S. ICAM-1 signaling in endothelial cells. Pharmacol Rep. 2009:61(1):22-32

32. Canobbio I, Abubaker AA, Visconte C, Torti M, Pula G. Role of amyloid peptides in vascular dysfunction and platelet dysregulation in Alzheimer's disease. Front Cell Neurosci. 2015;9:65.

33. Tchalla AE, Wellenius GA, Sorond FA, Gagnon M, lloputaife I, Travison TG, Dantoine T, Lipsitz LA. Elevated soluble vascular cell adhesion molecule-1 is associated with cerebrovascular resistance and cognitive function. J Gerontol A Biol Sci Med Sci. 2016;72(4):560-6.

34. Calabresi L, Gomaraschi M, Villa B, Omoboni L, Dmitrieff C, Franceschini G Elevated soluble cellular adhesion molecules in subjects with low HDLcholesterol. Arterioscler Thromb Vasc Biol. 2002;22(4):656-61.

35. Qosa H, Abuasal BS, Romero IA, Weksler B, Couraud P-O, Keller JN Kaddoumi A. Differences in amyloid- $\beta$ clearance across mouse and human blood-brain barrier models: kinetic analysis and mechanistic modeling. Neuropharmacology. 2014;79:668-78

36. Liu C-C, Zhao N, Yamaguchi Y, Cirrito JR, Kanekiyo T, Holtzman DM, Bu G Neuronal heparan sulfates promote amyloid pathology by modulating brain amyloid- $\beta$ clearance and aggregation in Alzheimer's disease. Sci Transl Med. 2016;8(332):332ra44

37. Rohrer L, Ohnsorg PM, Lehner M, Landolt F, Rinninger F, von Eckardstein A. High-density lipoprotein transport through aortic endothelial cells involves scavenger receptor $\mathrm{BI}$ and ATP-binding cassette transporter G1. Circ Res. 2009;104(10):1142-50 
38. Rajendran P, Rengarajan T, Thangavel J, Nishigaki Y, Sakthisekaran D, Sethi G, Nishigaki I. The vascular endothelium and human diseases. Int J Biol Sci. 2013;9(10):1057-69.

39. Snyder HM, Corriveau RA, Craft S, Faber JE, Greenberg SM, Knopman D, Lamb BT, Montine TJ, Nedergaard M, Schaffer CB, Schneider JA, Wellington C, Wilcock DM, Zipfel GJ, Zlokovic B, Bain L, Bosetti F, Galis ZS, Koroshetz W, Carrillo MC. Vascular contributions to cognitive impairment and dementia including Alzheimer's disease. Alzheimers Dement. 2015;11(6):710-7.

40. Raz L, Knoefel J, Bhaskar K. The neuropathology and cerebrovascular mechanisms of dementia. J Cereb Blood Flow Metab. 2016;36(1):172-86.

41. Thanopoulou K, Fragkouli A, Stylianopoulou F, Georgopoulos S. Scavenger receptor class B type I (SR-BI) regulates perivascular macrophages and modifies amyloid pathology in an Alzheimer mouse model. Proc Natl Acad Sci U S A. 2010;107(48):20816-21.

42. Giri R, Selvaraj S, Miller CA, Hofman F, Yan SD, Stern D, Zlokovic BV, Kalra VK Effect of endothelial cell polarity on beta-amyloid-induced migration of monocytes across normal and AD endothelium. Am J Physiol Cell Physiol. 2002;283(3):C895-904.

43. Lamoke F, Mazzone V, Persichini T, Maraschi A, Harris MB, Venema RC, Colasanti M, Gliozzi M, Muscoli C, Bartoli M, Mollace V. Amyloid $\beta$ peptideinduced inhibition of endothelial nitric oxide production involves oxidative stress-mediated constitutive eNOS/HSP90 interaction and disruption of agonist-mediated Akt activation. J Neuroinflammation. 2015;12:84.

44. Katusic ZS, Austin SA. Endothelial nitric oxide: protector of a healthy mind. Eur Heart J. 2014;35(14):888-94.

45. Kanekiyo T, Xu H, Bu G. ApoE and Abeta in Alzheimer's disease: accidental encounters or partners. Neuron. 2014;81(4):740-54.

46. Wilson LM, Pham CLL, Jenkins AJ, Wade JD, Hill AF, Perugini MA, Howlett GJ. High density lipoproteins bind Abeta and apolipoprotein C-II amyloid fibrils. J Lipid Res. 2006;47(4):755-60.

47. Terakawa MS, Yagi H, Adachi M, Lee Y-H, Goto Y. Small liposomes accelerate the fibrillation of amyloid $\beta$ (1-40). J Biol Chem. 2015;290(2):815-26.

48. Truran S, Weissig V, Madine J, Davies HA, Guzman-Villanueva D, Franco DA Karamanova N, Burciu C, Serrano G, Beach TG, Migrino RQ. Nanoliposomes protect against human arteriole endothelial dysfunction induced by $\beta$ amyloid peptide. J Cereb Blood Flow Metab. 2015;36(2):405-12.

49. Di Angelantonio E, Sarwar N, Perry P, Kaptoge S, Ray KK, Thompson A, Wood AM, Lewington S, Sattar N, Packard CJ, Collins R, Thompson SG, Danesh J. major Lipids, apolipoproteins, and risk of vascular disease. JAMA. 2009;302(18):1993-2000.

50. Stukas S, Robert J, Lee M, Kulic I, Carr M, Tourigny K, Fan J, Namjoshi D, Lemke K, DeValle N, Chan J, Wilson T, Wilkinson A, Chapanian R, Kizhakkedathu JN, Cirrito JR, Oda MN, Wellington CL. Intravenously injected human apolipoprotein A-I rapidly enters the central nervous system via the choroid plexus. J Am Heart Assoc. 2014;3(6):e001156.

\section{Submit your next manuscript to BioMed Central and we will help you at every step:}

- We accept pre-submission inquiries

- Our selector tool helps you to find the most relevant journal

- We provide round the clock customer support

- Convenient online submission

- Thorough peer review

- Inclusion in PubMed and all major indexing services

- Maximum visibility for your research

Submit your manuscript at www.biomedcentral.com/submit 